Supporting information for:

\title{
Role of Electron-Deficient Imidazoles on Ion Transport and Conductivity in Solid-State Polymer Electrolytes
}

Andrei Nikolaev, ${ }^{\text {ad }}$ Peter M. Richardson, ${ }^{\text {cd }}$ Shuyi Xie, ${ }^{\text {cd }}$ Luana Canzian Llanes, ${ }^{\text {adf }}$ Seamus D. Jones, ${ }^{\text {ce }}$ Oscar Nordness, ${ }^{\text {cd }}$ Hengbin Wang, ${ }^{d}$ Guillermo Bazan, ${ }^{f}$ Rachel A. Segalman, ${ }^{* b c d e}$ Raphaële J. Clément, ${ }^{*}$ bcd and Javier Read de Alaniz*a

a Department of Chemistry and Biochemistry, University of California at Santa Barbara, Santa Barbara, California 93106, United States

b Materials Department, University of California at Santa Barbara, Santa Barbara, California 93106, United States

c Materials Research Laboratory, University of California at Santa Barbara, Santa Barbara, California 93106, United States

d Mitsubishi Chemical Center for Advanced Materials, University of California at Santa Barbara, Santa Barbara, California 93106, United States

e Department of Chemical Engineering, University of California at Santa Barbara, Santa Barbara, California 93106, United States

${ }^{f}$ Center for Polymers and Organic Solids, University of California at Santa Barbara, Santa Barbara, California 93106, United States

*Corresponding authors

E-mail: javier@chem.ucsb.edu,segalman@ucsb.edu,rclement@ucsb.edu

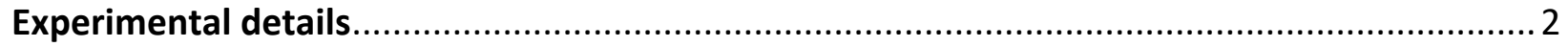

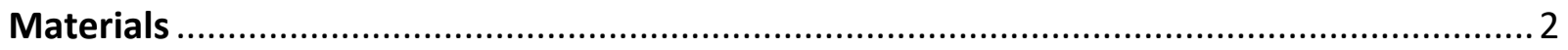

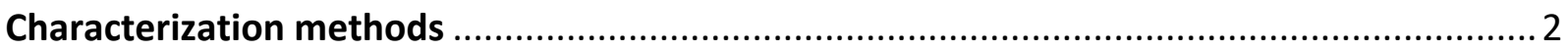

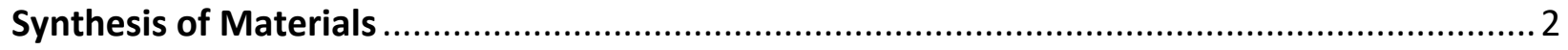

Synthesis of imidazole derivative-containing side chains .......................................... 2

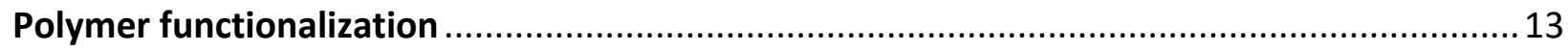

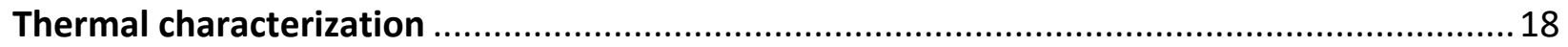

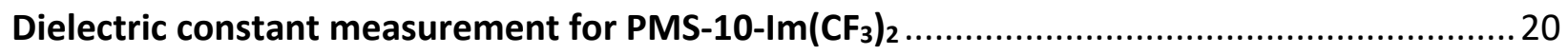

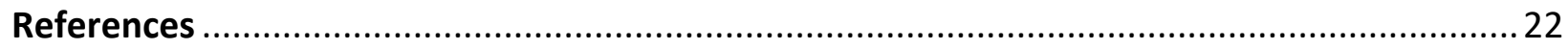




\section{Experimental details}

\section{Materials}

Unless stated otherwise, reactions were conducted under a nitrogen atmosphere using reagent grade solvents. All commercially-obtained reagents were used without purification, unless noted. Furfural was distilled before use and stored at $-18{ }^{\circ} \mathrm{C}$. Analytical thin-layer chromatography (TLC) was carried out with Merck silica gel 60 F254 glass plates and visualized using combination of UV and potassium permanganate staining or $p$-anisaldehyde. Flash column chromatography was performed with Merck silica gel 60 (70-230 mesh). All chromatographic solvents were of ACS grade and used without further purification. $25 \mu \mathrm{m}$ thick Polyimide (Kapton ${ }^{\circledR}$, 2271K-1, McMaster-Carr) film without adhesive was purchased.

\section{Characterization methods}

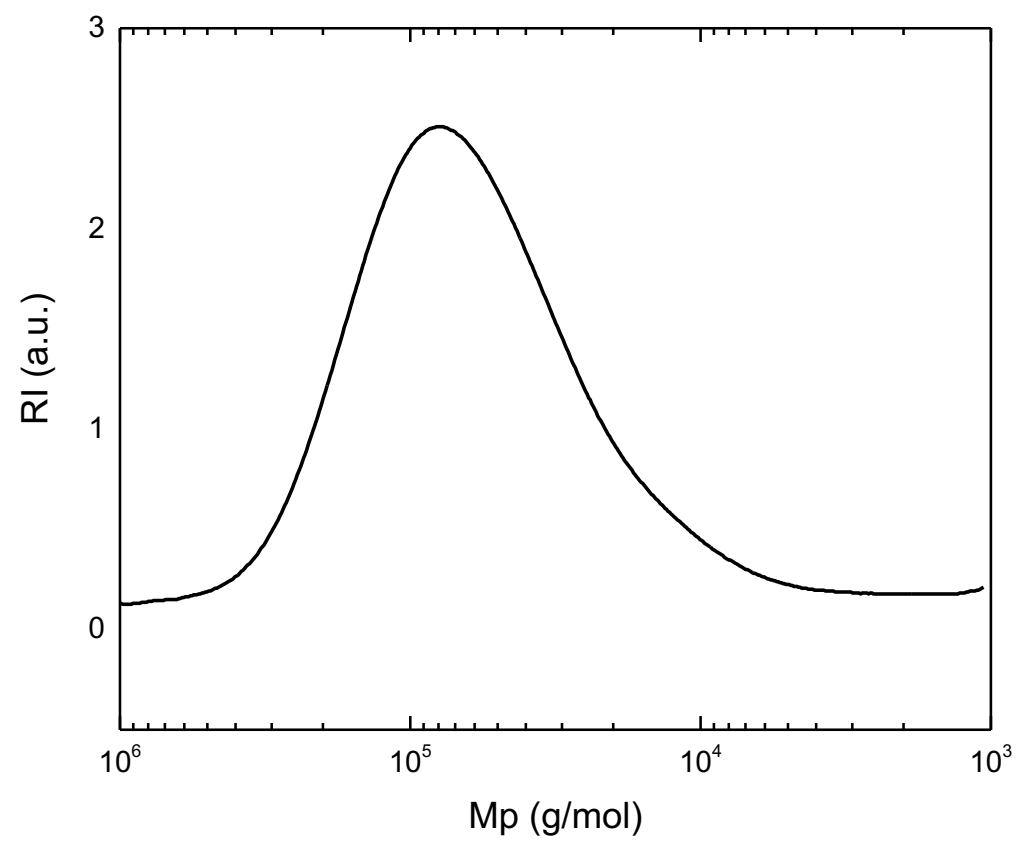

Figure S1. Refractive index (RI) trace for PVMS. The molecular weight distribution was calculated by polystyrene calibration. $M_{\mathrm{w}}=101 \mathrm{~kg} / \mathrm{mol}, M_{\mathrm{n}}=55 \mathrm{~kg} / \mathrm{mol}$ and $\Theta=1.82$

\section{Synthesis of Materials}

\section{Synthesis of imidazole derivative-containing side chains}

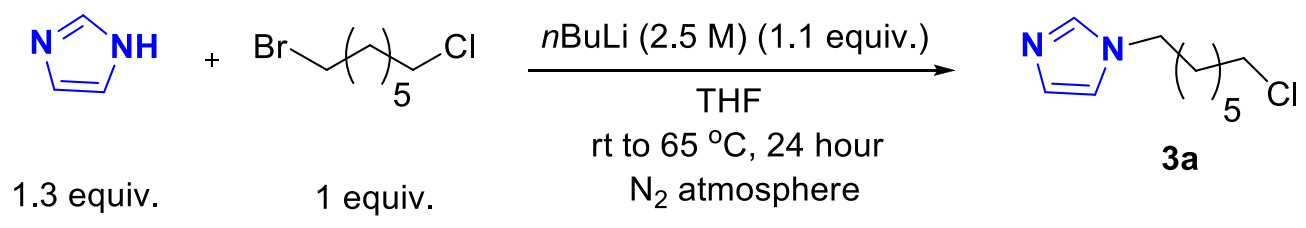


Synthesis of 1-(7-chloroheptyl)-1H-imidazole (3a): To an oven dried round bottom flask equipped with a magnetic stir bar, imidazole (1.3 equiv.) and half the total volume of THF was added 1.1 equiv. of $2.5 \mathrm{M} \mathrm{nBuLi}$ in hexane at ambient temperature. This solution was stirred for 30 minutes at ambient temperature under dinitrogen atmosphere. To this reaction was added a solution of 1-bromo-7-chloroheptane in THF to a final concentration of $0.6 \mathrm{M}$ in imidazole. This reaction mixture was placed in an oil bath preheated to $65{ }^{\circ} \mathrm{C}$ and stirred for 24 hours under dinitrogen atmosphere. Upon completion, the reaction was filtered through a pad of silica and concentrated in vacuo. The (7-chloroheptyl)-imidazole was purified by flash column chromatography, eluting with 4:6 EtOAc:Hexanes and isolated in $85 \%$ yield. The ${ }^{1} \mathrm{H}-\mathrm{NMR}$ data mached that of previously reported. ${ }^{1}$

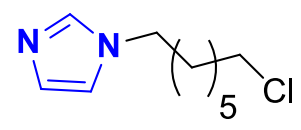

1 equiv.

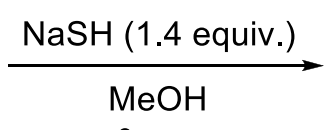

$65^{\circ} \mathrm{C}, 20 \mathrm{~h}$

$\mathrm{N}_{2}$ atmosphere

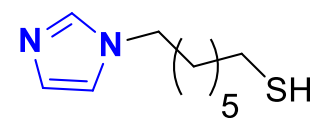

$4 a$

Synthesis of 7-(1H-imidazol-1-yl)heptane-1-thiol (4a): To an oven dried round bottom flask equipped with a magnetic stir bar was added $\mathrm{NaSH}$ (1.4 equiv.) followed by a $0.5 \mathrm{M}$ solution of 1-(7-chloroheptyl)-imidazole in deoxygenated absolute $\mathrm{MeOH}$ at ambient temperature. This reaction mixture was placed in an oil bath preheated to $65{ }^{\circ} \mathrm{C}$ and stirred for 20 hours under dinitrogen atmosphere. Upon completion, the reaction was filtered through a pad of celite and concentrated in vacuo. The 7-(1H-imidazol-1-yl)heptane-1-thiol was used for the thiol-ene click reaction with polyvinyl methyl siloxane (PVMS) without further purification.<smiles>Clc1nc[nH]c1Cl</smiles>

1.3 equiv.<smiles>CC(C)(CCl)CBr</smiles>

1 equiv.

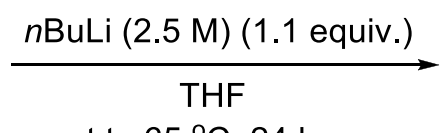

rt to $65^{\circ} \mathrm{C}, 24$ hour

$\mathrm{N}_{2}$ atmosphere

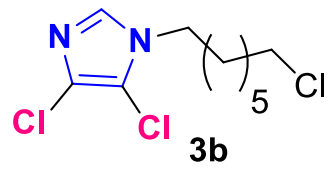

$3 \mathbf{b}$

Synthesis of 4,5-dichloro-1-(7-chloroheptyl)-1H-imidazole (3b): To an oven dried round bottom flask equipped with a magnetic stir bar, 4,5-dichloroimidazole (1.3 equiv.) and half the total volume of THF was added 1.1 equiv. of $2.5 \mathrm{M} \mathrm{nBuLi}$ in hexane at ambient temperature. This solution was stirred for 30 minutes at ambient temperature under dinitrogen atmosphere. To this reaction was added a solution of 1-bromo-7-chloroheptane in THF to a final concentration of $0.6 \mathrm{M}$ in 4,5-dichloroimidazole. This reaction mixture was placed in an oil bath preheated to 65 ${ }^{\circ} \mathrm{C}$ and stirred for 24 hours under dinitrogen atmosphere. Upon completion, the reaction was filtered through a pad of silica and concentrated in vacuo. The 4,5-dichloro-1-(7-chloroheptyl)imidazole was purified by flash column chromatography, eluting with 3:7 EtOAc:Hexanes and isolated in $85 \%$ yield. ${ }^{1} \mathrm{H}-\mathrm{NMR}\left(500 \mathrm{MHz}, \mathrm{CDCl}_{3}\right) \delta 7.40(\mathrm{~s}, 1 \mathrm{H}), 3.91(\mathrm{t}, J=7.2 \mathrm{~Hz}, 2 \mathrm{H}), 3.53(\mathrm{t}, J=$ $6.6 \mathrm{~Hz}, 2 \mathrm{H}), 1.78(\mathrm{~m}, 4 \mathrm{H}), 1.45(\mathrm{~m}, 2 \mathrm{H}), 1.35(\mathrm{~m}, 5 \mathrm{H}) .{ }^{13} \mathrm{C}-\mathrm{NMR}\left(125 \mathrm{MHz}, \mathrm{CDCl}_{3}\right) \delta$ 134.1, 125.9, 
113.1, 46.2, 44.9, 32.3, 29.9, 28.2, 26.5, 26.1. Calculated for $\mathrm{M}+\mathrm{Na}^{+}:\left[\mathrm{C}_{10} \mathrm{H}_{15} \mathrm{Cl}_{3} \mathrm{~N}_{2} \mathrm{Na}\right]=291.0199$, found 291.0195 .

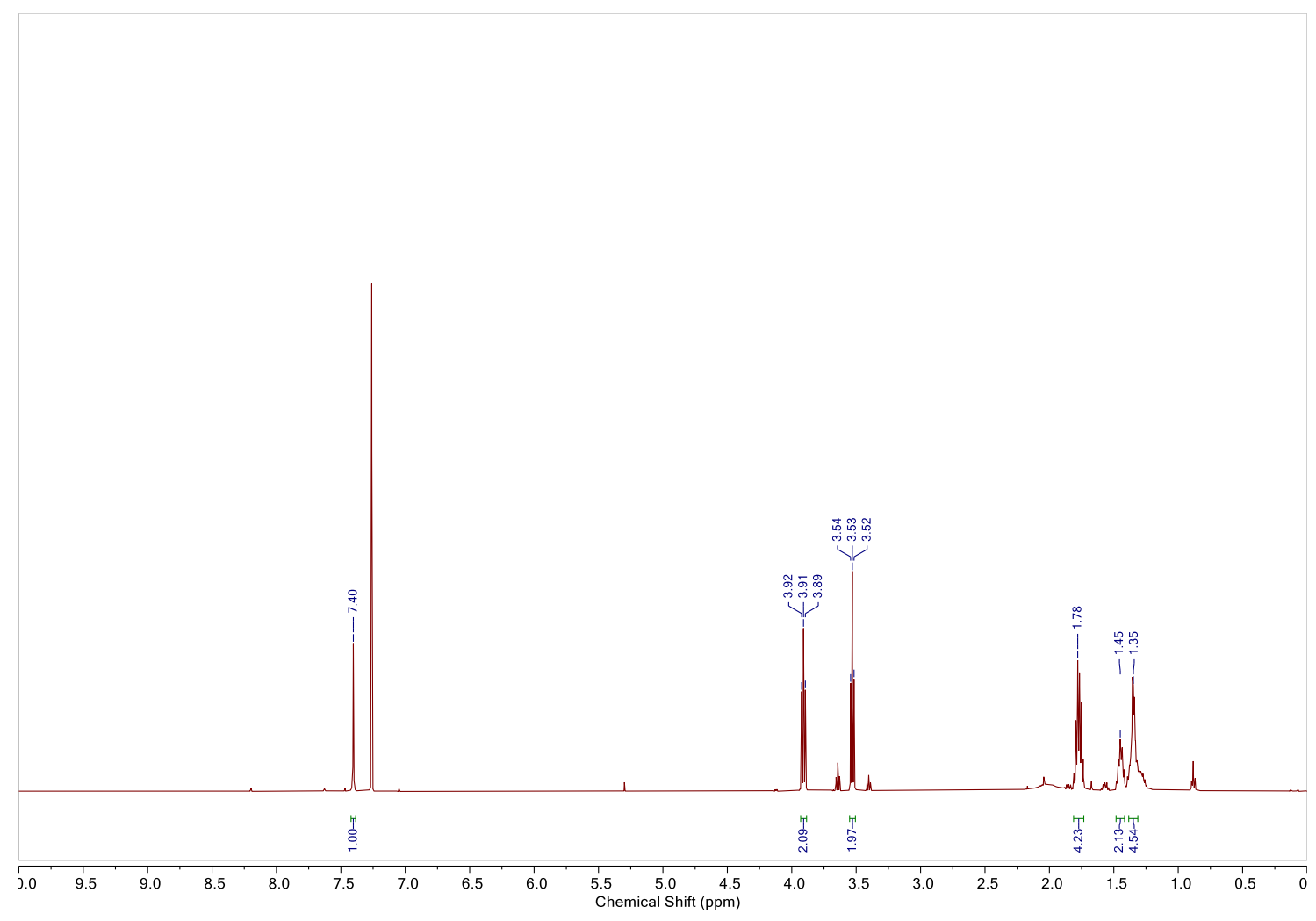

Figure S2. ${ }^{1} \mathrm{H}-\mathrm{NMR}$ of 4,5-dichloro-1-(7-chloroheptyl)-1H-imidazole (3b) 

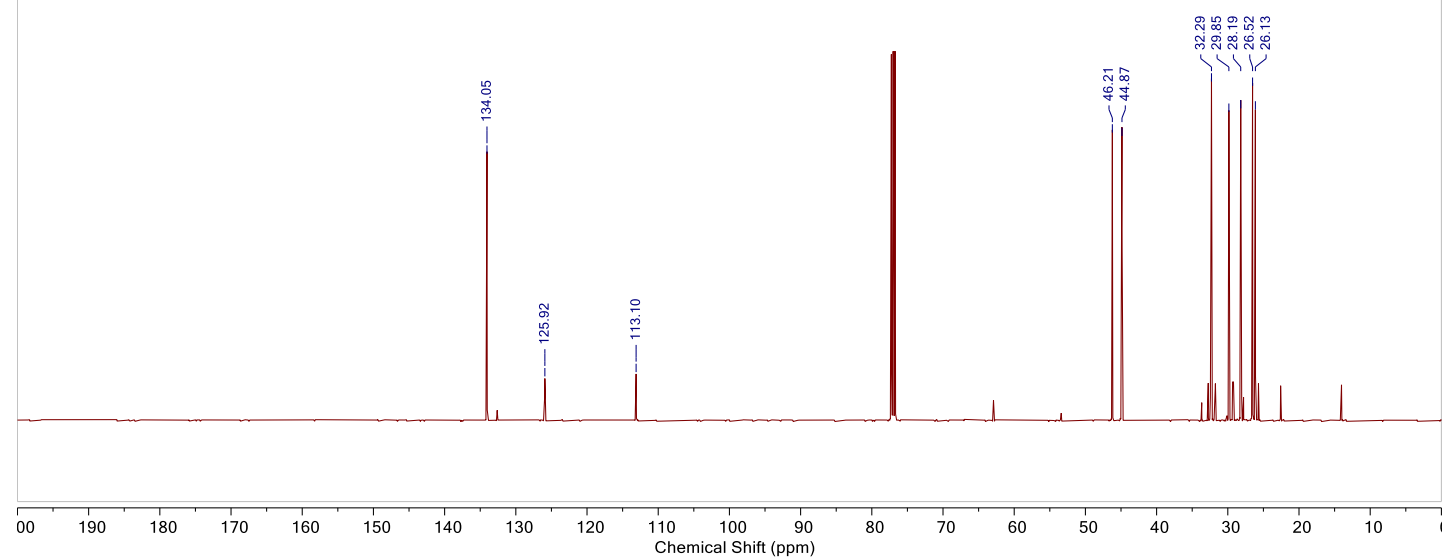

Figure S3. ${ }^{13} \mathrm{C}-\mathrm{NMR}$ of 4,5-dichloro-1-(7-chloroheptyl)-1H-imidazole (3b)<smiles>CC(C)(CCl)Cn1cnc(Cl)c1Cl</smiles>

1 equiv.

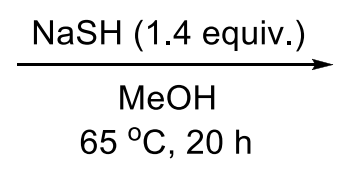

$\mathrm{N}_{2}$ atmosphere

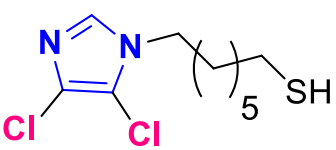

4b

Synthesis of 7-(4,5-dichloro-1H-imidazol-1-yl)heptane-1-thiol (4b): To an oven dried round bottom flask equipped with a magnetic stir bar was added $\mathrm{NaSH}$ (1.4 equiv.) followed by a $0.5 \mathrm{M}$ solution of 4,5-dichloro-1-(7-chloroheptyl)-imidazole in deoxygenated absolute $\mathrm{MeOH}$ at ambient temperature. This reaction mixture was placed in an oil bath preheated to $65{ }^{\circ} \mathrm{C}$ and stirred for 20 hours under dinitrogen atmosphere. Upon completion, the reaction was filtered through a pad of celite and concentrated in vacuo. The 7-(4,5-dichloro-1H-imidazol-1-yl)heptane1-thiol was used for the thiol-ene click reaction with polyvinyl methyl siloxane (PVMS) without further purification.<smiles>FC(F)(F)c1nc[nH]c1C(F)(F)F</smiles>

1.3 equiv.<smiles>CC(C)(CCl)CBr</smiles>

1 equiv.

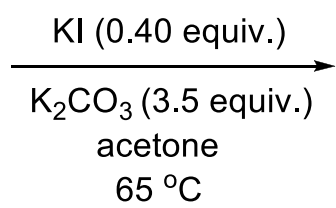

$24 \mathrm{~h}, \mathrm{~N}_{2}$<smiles>CC(C)(CCl)C(C)(C)Cn1cnc(C(F)(F)F)c1C(F)(F)F</smiles>

$3 c$ 
Synthesis of 1-(7-chloroheptyl)-4,5-bis(trifluoromethyl)-imidazole (3c): To an oven dried round bottom flask equipped with a magnetic stir bar, 4,5-bis(trifluoromethyl)-imidazole, 1-bromo-7chloroheptane (1.0 equiv.), potassium iodide ( 0.4 equiv.), potassium carbonate (3.5 equiv.), and acetone were added. This reaction mixture was placed in an oil bath preheated to $65{ }^{\circ} \mathrm{C}$ and stirred for 24 hours under dinitrogen atmosphere. Upon completion, the reaction was filtered through a pad of celite and concentrated in vacuo. The 1-(7-chloroheptyl)-4,5bis(trifluoromethyl)-imidazole was purified by flash column chromatography, eluting with 3:7 EtOAc:Hexanes and isolated in $86 \%$ yield. ${ }^{1} \mathrm{H}-\mathrm{NMR}\left(500 \mathrm{MHz}, \mathrm{CDCl}_{3}\right) \delta 7.58(\mathrm{~s}, 1 \mathrm{H}), 4.09(\mathrm{t}, J=7.5$ $\mathrm{Hz}, 2 \mathrm{H}), 3.53(\mathrm{t}, J=6.6 \mathrm{~Hz}, 2 \mathrm{H}), 1.86(\mathrm{~m}, 2 \mathrm{H}), 1.77(\mathrm{~m}, 2 \mathrm{H}), 1.42(\mathrm{~m}, 6 \mathrm{H}) .{ }^{13} \mathrm{C}-\mathrm{NMR}\left(125 \mathrm{MHz}, \mathrm{CDCl}_{3}\right)$ $\delta 134.0,133.2\left(q,{ }^{3} J_{C-F}=43 \mathrm{~Hz}\right), 120.3\left(q,{ }^{1} J_{C-F}=268 \mathrm{~Hz}\right), 119.7\left(q,{ }^{3} J_{C-F}=40 \mathrm{~Hz}\right), 119.6\left(q,{ }^{1} J_{C-F}=\right.$ $270 \mathrm{~Hz}), 47.4,44.8,32.2,30.4,28.0,26.4,26.2 .{ }^{19} \mathrm{~F}-\mathrm{NMR}\left(376 \mathrm{MHz}, \mathrm{CDCl}_{3}\right) \delta-57.18,-60.87$. Calculated for $\mathrm{M}+\mathrm{H}^{+}:\left[\mathrm{C}_{12} \mathrm{H}_{16} \mathrm{ClF}_{6} \mathrm{~N}_{2}\right]=337.0906$, found 337.0908 .

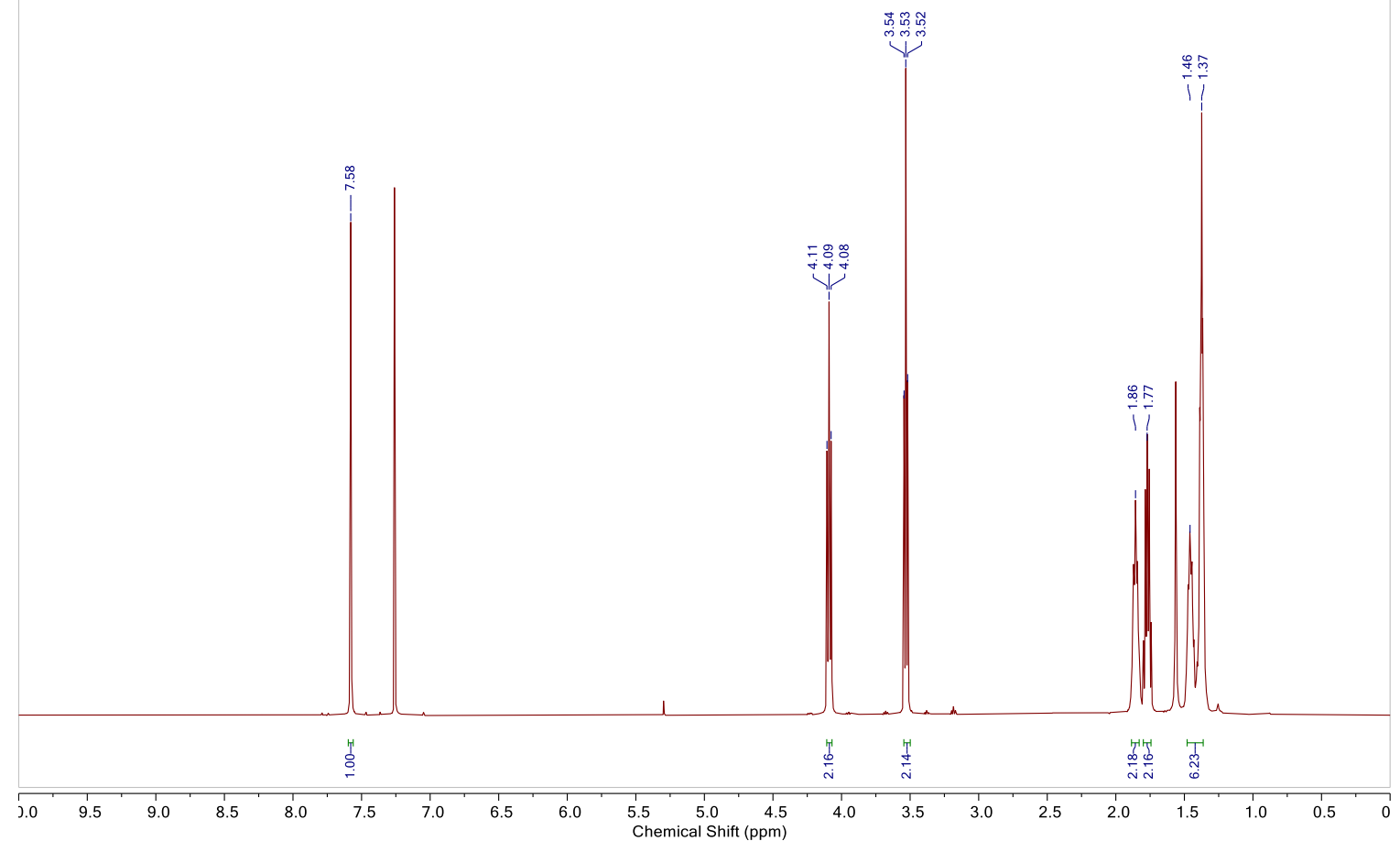

Figure S4. ${ }^{1} \mathrm{H}-\mathrm{NMR}$ of 1-(7-chloroheptyl)-4,5-bis(trifluoromethyl)-imidazole (3c) 


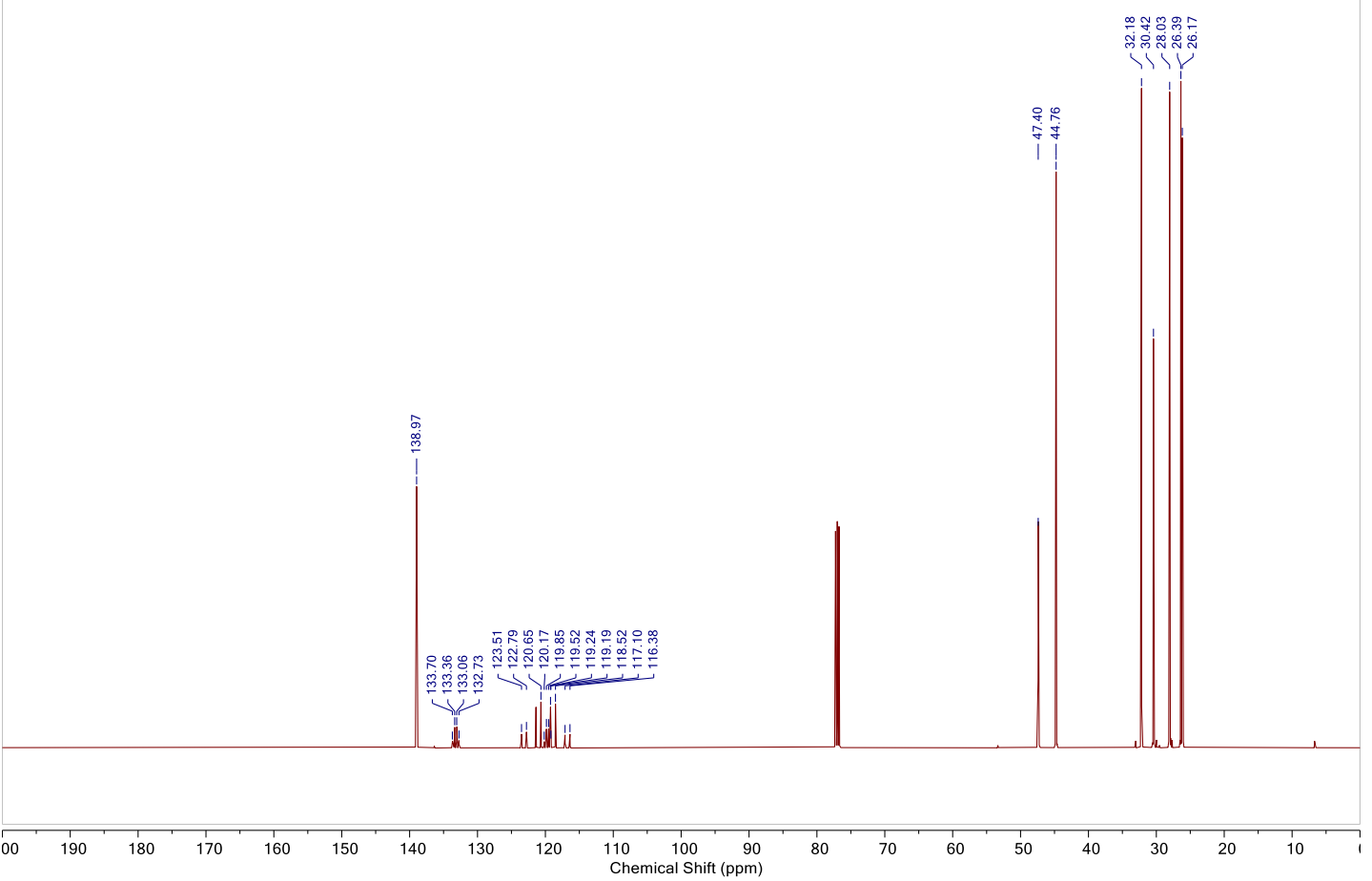

Figure S5. ${ }^{13} \mathrm{C}-\mathrm{NMR}$ of 1-(7-chloroheptyl)-4,5-bis(trifluoromethyl)-imidazole (3c)

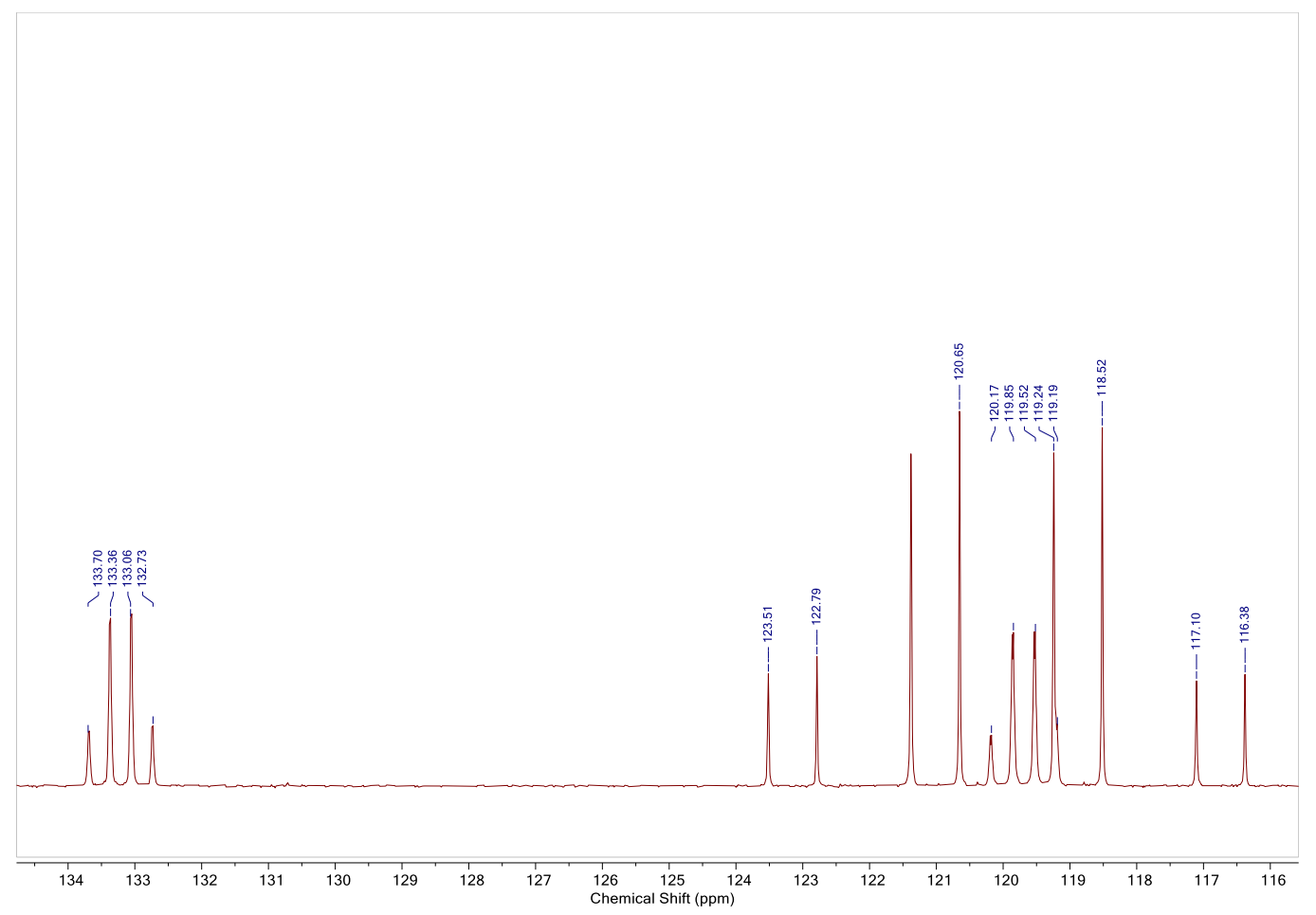

Figure S6. Expanded ${ }^{13} \mathrm{C}-\mathrm{NMR}$ spectrum of 3c. 


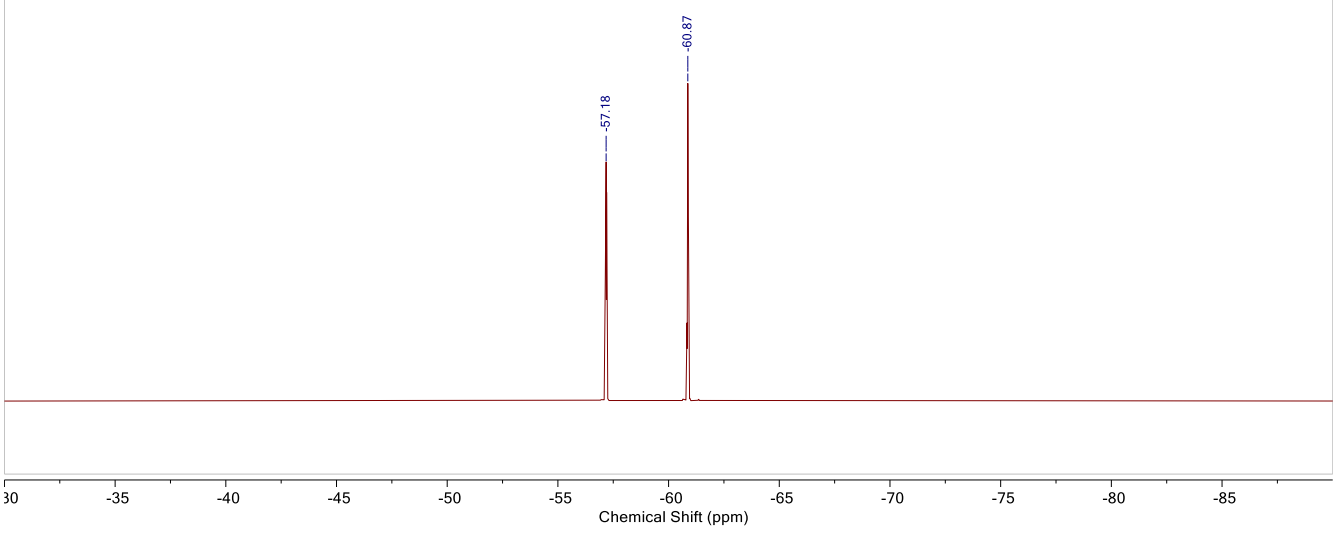

Figure S7. ${ }^{19} \mathrm{~F}-\mathrm{NMR}$ of 1-(7-chloroheptyl)-4,5-bis(trifluoromethyl)-imidazole (3c)

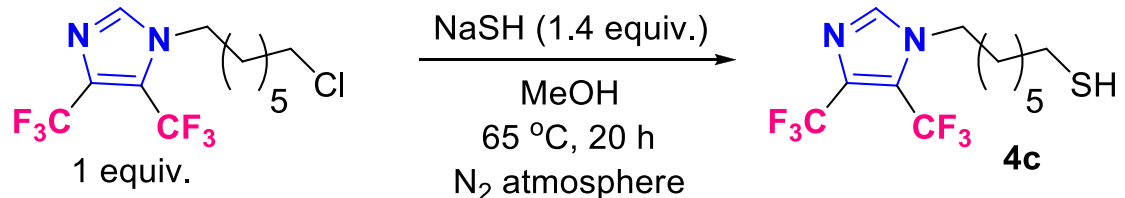

Synthesis of 7-(4,5-bis(trifluoromethyl)-1H-imidazol-1-yl)heptane-1-thiol (4c): To an oven dried round bottom flask equipped with a magnetic stir bar was added $\mathrm{NaSH}$ (1.4 equiv.) followed by a $0.5 \mathrm{M}$ solution of 4,5-dichloro-1-(7-chloroheptyl)-imidazole in deoxygenated absolute $\mathrm{MeOH}$ at ambient temperature. This reaction mixture was placed in an oil bath preheated to $65{ }^{\circ} \mathrm{C}$ and stirred for 20 hours under dinitrogen atmosphere. Upon completion, the reaction was filtered through a pad of celite and concentrated in vacuo. The 7-(4,5-bis(trifluoromethyl)-1H-imidazol-1$y$ l)heptane-1-thiol was used for the thiol-ene click reaction with polyvinyl methyl siloxane (PVMS) without further purification.<smiles>Brc1nc(Br)c(Br)[nH]1</smiles>

1.3 equiv.<smiles>CC(C)(CCl)CBr</smiles>

1 equiv.
$\mathrm{NaH}$ (3.00 equiv.)

THF rt to $65^{\circ} \mathrm{C}$ $24 \mathrm{~h}, \mathrm{~N}_{2}$<smiles>CC(C)(CCl)Cn1c(Br)nc(Br)c1Br</smiles> 
Synthesis of 2,4,5-tribromo-1-(7-chloroheptyl)-1H-imidazole (3d): To an oven dried round bottom flask equipped with a magnetic stir bar, 2,4,5-tribromoimidazole (1.3 equiv.), 1-bromo7-chloroheptane (1.0 equiv.), and THF were added. To this solution was added $\mathrm{NaH}$ (3.00 equiv.) portions wise. This reaction mixture was placed in an oil bath preheated to $65{ }^{\circ} \mathrm{C}$ and stirred for 24 hours under dinitrogen atmosphere. Upon completion, the reaction was filtered through a pad of celite and concentrated in vacuo. The 2,4,5-tribromo-1-(7-chloroheptyl)-imidazole was purified by flash column chromatography, eluting with 2:8 EtOAc:Hexanes solventB and isolated in $75 \%$ yield. ${ }^{1} \mathrm{H} N M R\left(500 \mathrm{MHz}, \mathrm{CDCl}_{3}\right) \delta 3.98(\mathrm{t}, J=7.4 \mathrm{~Hz}, 2 \mathrm{H}), 3.54(\mathrm{t}, J=6.6 \mathrm{~Hz}, 2 \mathrm{H}), 1.76(\mathrm{~m}$, $4 \mathrm{H}), 1.47(\mathrm{~m}, 2 \mathrm{H}), 1.37(\mathrm{~m}, 4 \mathrm{H}) .{ }^{13} \mathrm{C} \mathrm{NMR}\left(125 \mathrm{MHz}, \mathrm{CDCl}_{3}\right) \delta 117.7,116.4,104.8,48.1,44.8,32.2$, 29.3, 28.1, 26.4, 26.0. Calculated for $\mathrm{M}+\mathrm{Na}^{+}$: $\left[\mathrm{C}_{10} \mathrm{H}_{14} \mathrm{Br}_{3} \mathrm{ClN}_{2} \mathrm{Na}\right]=456.8293$, found 456.8295 .

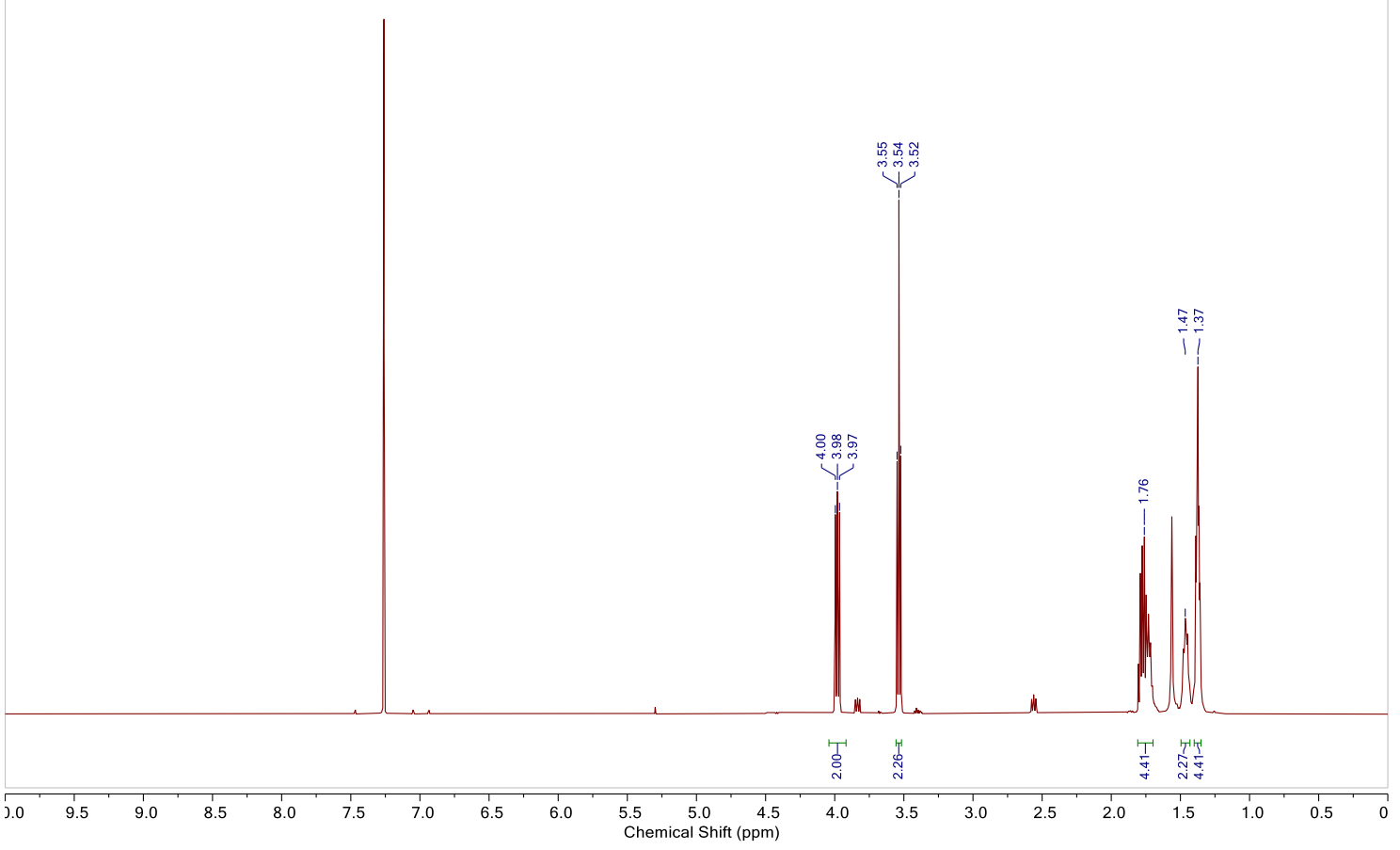

Figure S8. ${ }^{1} \mathrm{H}-\mathrm{NMR}$ of 2,4,5-tribromo-1-(7-chloroheptyl)-1H-imidazole (3d) 


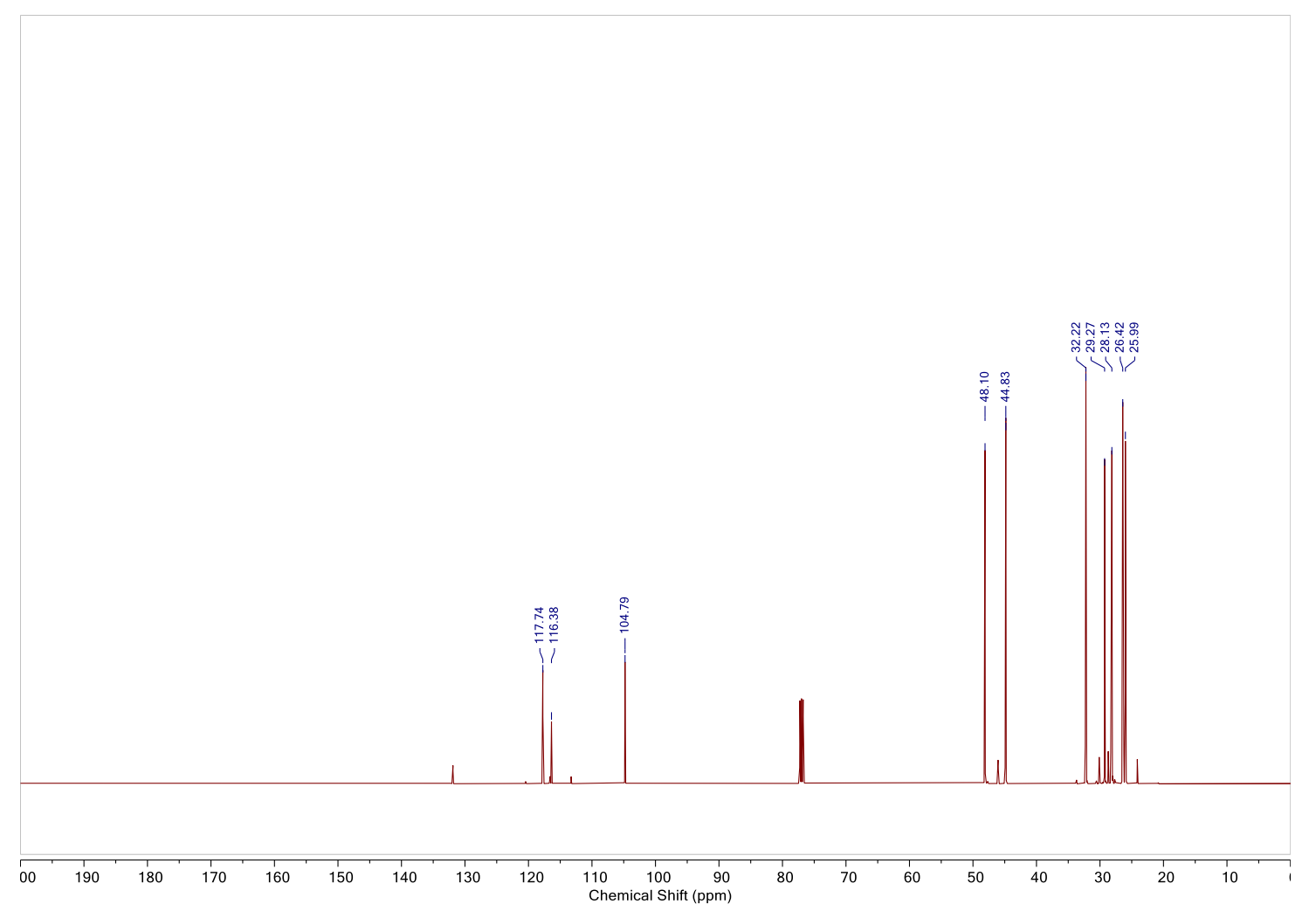

Figure S9. ${ }^{13} \mathrm{C}-\mathrm{NMR}$ of 2,4,5-tribromo-1-(7-chloroheptyl)-1H-imidazole (3d)
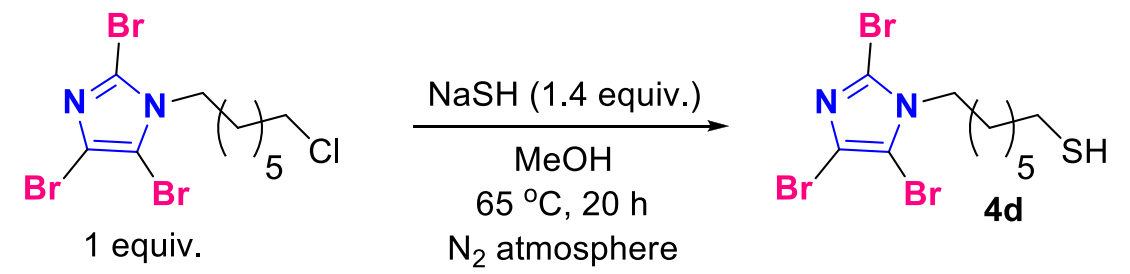

Synthesis of 7-(2,4,5-tribromo-1H-imidazol-1-yl)heptane-1-thiol (4d): To an oven dried round bottom flask equipped with a magnetic stir bar was added $\mathrm{NaSH}$ (1.4 equiv.) followed by a $0.5 \mathrm{M}$ solution of 2,4,5-tribromo-1-(7-chloroheptyl)-imidazole in deoxygenated absolute $\mathrm{MeOH}$ at ambient temperature. This reaction mixture was placed in an oil bath preheated to $65{ }^{\circ} \mathrm{C}$ and stirred for 20 hours under dinitrogen atmosphere. Upon completion, the reaction was filtered through a pad of celite and concentrated in vacuo. The 7-(2,4,5-tribromo-1H-imidazol-1yl)heptane-1-thiol was used for the thiol-ene click reaction with polyvinyl methyl siloxane (PVMS) without further purification. 
<smiles>Clc1nc(Br)[nH]c1Cl</smiles>

1.3 equiv.<smiles>CC(C)(CCl)CBr</smiles>

1 equiv.

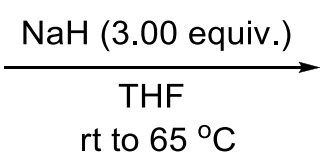

$24 \mathrm{~h}, \mathrm{~N}_{2}$

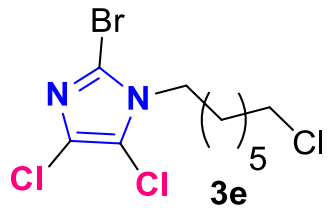

$3 e$

Synthesis of 2-bromo-4,5-dichloro-1-(7-chloroheptyl)-1H-imidazole (3e): To an oven dried round bottom flask equipped with a magnetic stir bar, 2-bromo-4,5-dichloroimidazole (1.3 equiv.), 1bromo-7-chloroheptane (1.0 equiv.), and THF were added. To this solution was added $\mathrm{NaH}$ (3.00 equiv.) portions wise. This reaction mixture was placed in an oil bath preheated to $65{ }^{\circ} \mathrm{C}$ and stirred for 24 hours under dinitrogen atmosphere. Upon completion, the reaction was filtered through a pad of celite and concentrated in vacuo. The 2-bromo-4,5-dichloro-1-(7-chloroheptyl)imidazole was purified by flash column chromatography, eluting with 1:9 EtOAc:Hexanes and isolated in $82 \%$ yield. ${ }^{1} \mathrm{H}-\mathrm{NMR}\left(500 \mathrm{MHz}, \mathrm{CDCl}_{3}\right) \delta 3.93(\mathrm{t}, J=7.4 \mathrm{~Hz}, 2 \mathrm{H}), 3.53(\mathrm{t}, J=6.6 \mathrm{~Hz}, 2 \mathrm{H})$, $1.68(\mathrm{~m}, 4 \mathrm{H}), 1.41(\mathrm{~m}, 2 \mathrm{H}), 1.33(\mathrm{~m}, 4 \mathrm{H}) .{ }^{13} \mathrm{C}-\mathrm{NMR}\left(125 \mathrm{MHz}, \mathrm{CDCl}_{3}\right) \delta 126.0,115.8,114.6,46.9$, $44.9,32.3,29.3,28.2,26.5,26.1$. Calculated for $\mathrm{M}+\mathrm{Na}^{+}$: $\left[\mathrm{C}_{10} \mathrm{H}_{14} \mathrm{BrCl}_{3} \mathrm{~N}_{2} \mathrm{Na}\right]=368.9304$, found 368.9306.

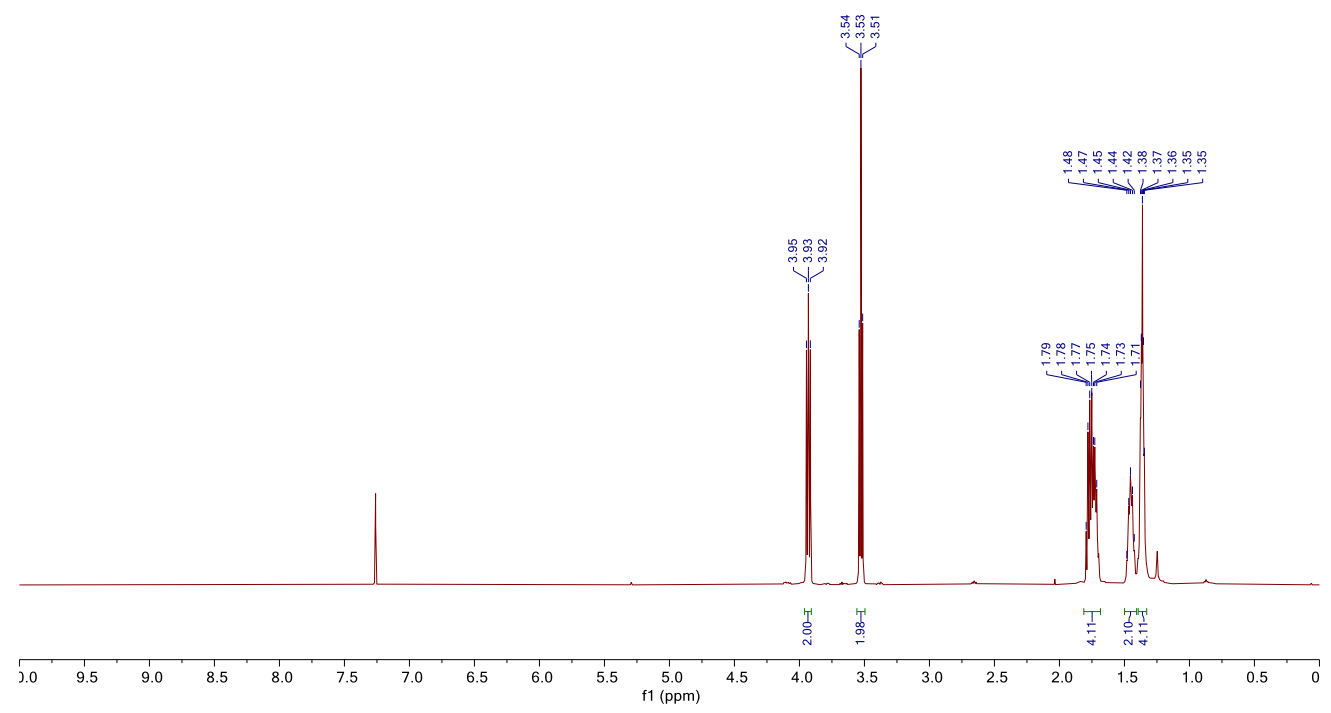

Figure S10. ${ }^{1} \mathrm{H}-\mathrm{NMR}$ of 2-bromo-4,5-dichloro-1-(7-chloroheptyl)-1H-imidazole (3e) 

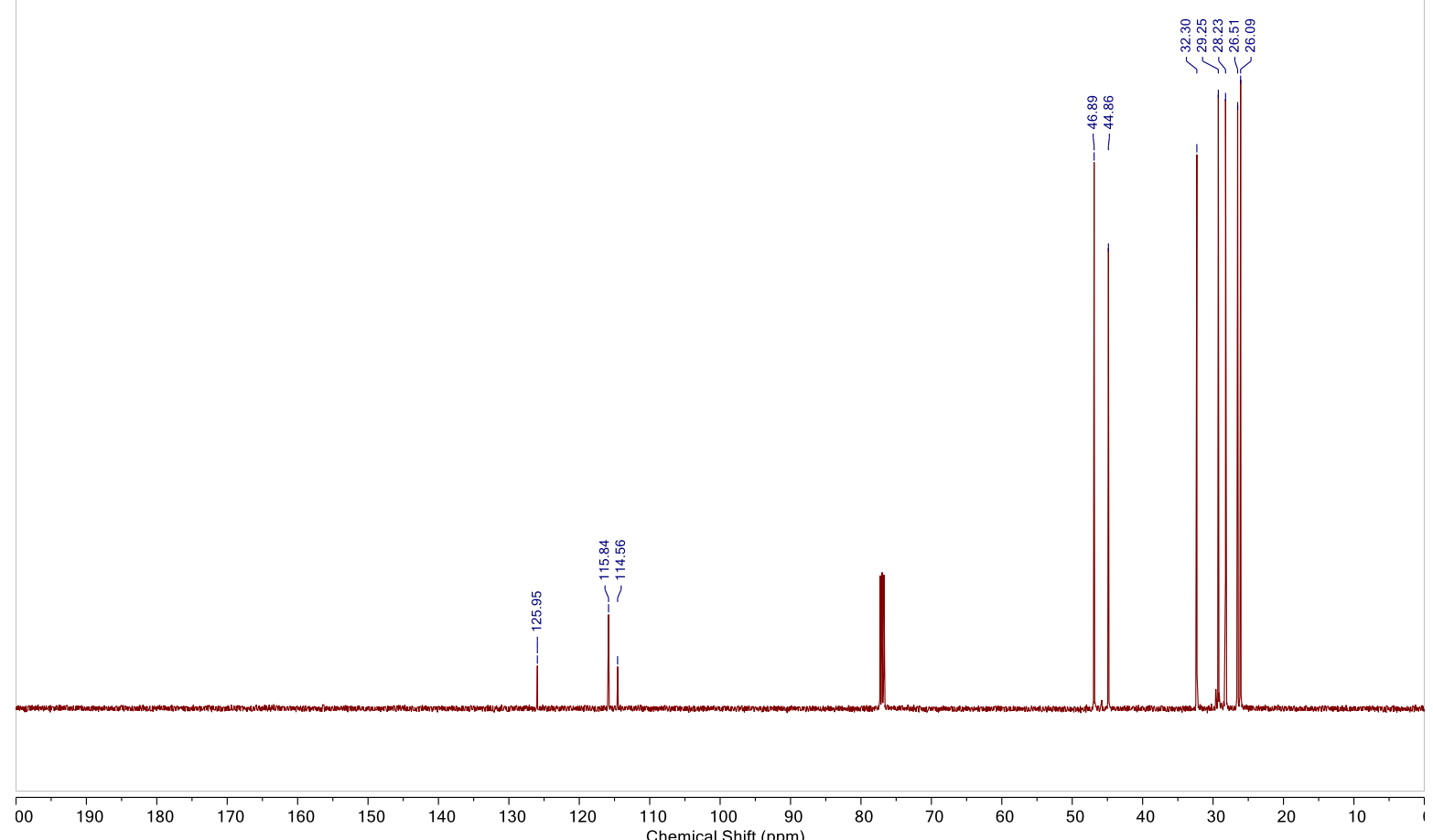

Figure S11. ${ }^{13} \mathrm{C}-\mathrm{NMR}$ of 2-bromo-4,5-dichloro-1-(7-chloroheptyl)-1H-imidazole (3e)<smiles>CC(C)(CCl)Cn1c(Br)nc(Cl)c1Cl</smiles>

1 equiv.

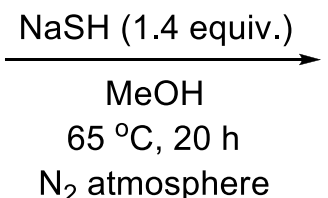

$\mathrm{N}_{2}$ atmosphere

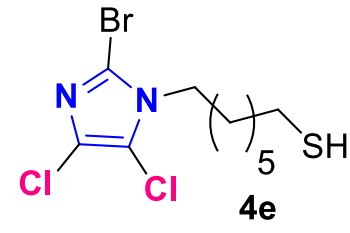

Synthesis of 7-(2-bromo-4,5-dichloro-1H-imidazol-1-yl)heptane-1-thiol (4e): To an oven dried round bottom flask equipped with a magnetic stir bar was added $\mathrm{NaSH}$ (1.4 equiv.) followed by a $0.5 \mathrm{M}$ solution of 2-bromo-4,5-dichloro-1-(7-chloroheptyl)-imidazole in deoxygenated absolute $\mathrm{MeOH}$ at ambient temperature. This reaction mixture was placed in an oil bath preheated to 65 ${ }^{\circ} \mathrm{C}$ and stirred for 20 hours under dinitrogen atmosphere. Upon completion, the reaction was filtered through a pad of celite and concentrated in vacuo. The 7-(2-bromo-4,5-dichloro- $1 \mathrm{H}$ imidazol-1-yl)heptane-1-thiol was used for the thiol-ene click reaction with polyvinyl methyl siloxane (PVMS) without further purification. 


\section{Polymer functionalization}

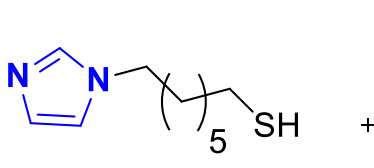

5 equiv.

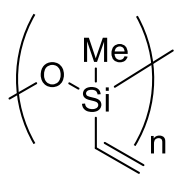

1 equiv.

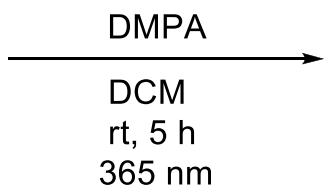

$\mathrm{N}_{2}$ atmosphere

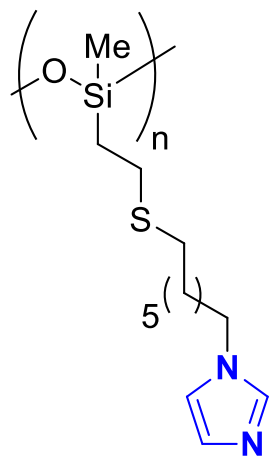

Synthesis of PMS-10-Im: To an oven dried round bottom flask equipped with a magnetic stir bar was added 7-(1H-imidazol-1-yl)heptane-1-thiol (5.0 equiv.), PVMS, DMPA (2,2-dimethoxy-2phenylacetophenone) (10 mol\%) followed by deoxygenated absolute DCM to concertation of 0.1 $M$ in PVMS. This reaction mixture was irradiated with $365 \mathrm{~nm}$ light for 5 hours. Upon completion, the crude mixture was concentrated in vacuo. The polymer was purified by precipitation in THF, then dried under high vacuum and immediately transferred to a nitrogen filled glove box. ${ }^{2}$<smiles>CCn1cnc(Cl)c1Cl</smiles>

5 equiv.

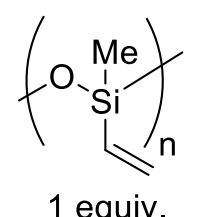

1 equiv.

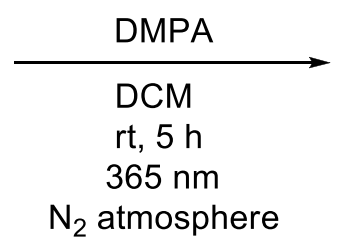

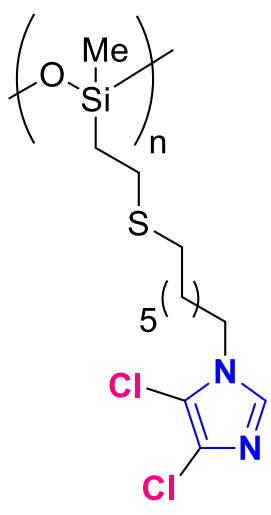

Synthesis of PMS-10-ImCl 2 : To an oven dried round bottom flask equipped with a magnetic stir bar was added 7-(4,5-dichloro-1H-imidazol-1-yl)heptane-1-thiol (5.0 equiv.), PVMS, DMPA (2,2dimethoxy-2-phenylacetophenone) (10 mol\%) followed by deoxygenated absolute DCM to concertation of $0.1 \mathrm{M}$ in PVMS. This reaction mixture was irradiated with $365 \mathrm{~nm}$ light for 5 hours. Upon completion, the crude mixture was concentrated in vacuo. The polymer was purified by precipitation in $\mathrm{MeOH}$, then dried under high vacuum and immediately transferred to a nitrogen filled glove box. 


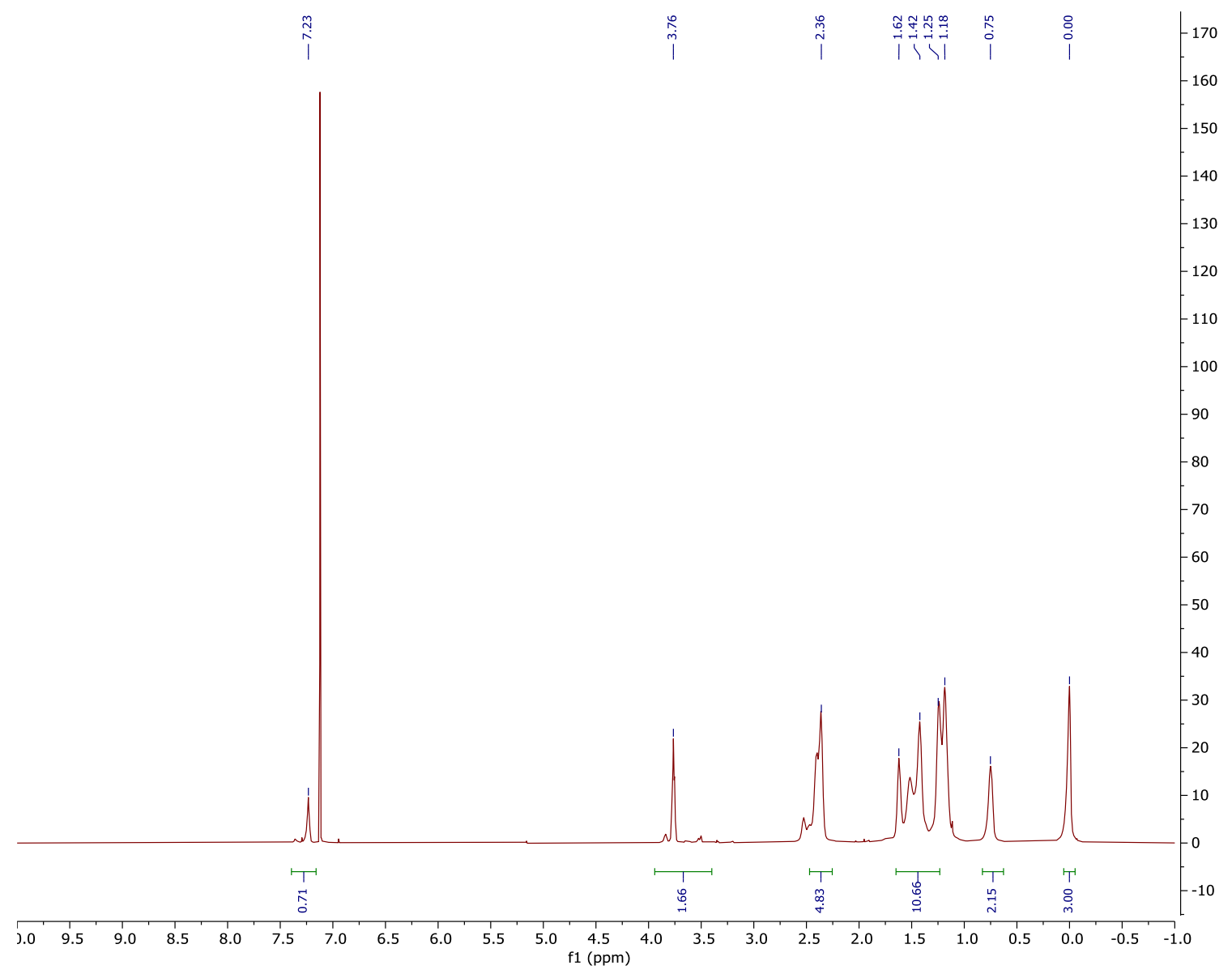

Figure S12. ${ }^{1} \mathrm{H}-\mathrm{NMR}$ of $\mathrm{PMS}-10-\mathrm{ImCl}{ }_{2}$ 

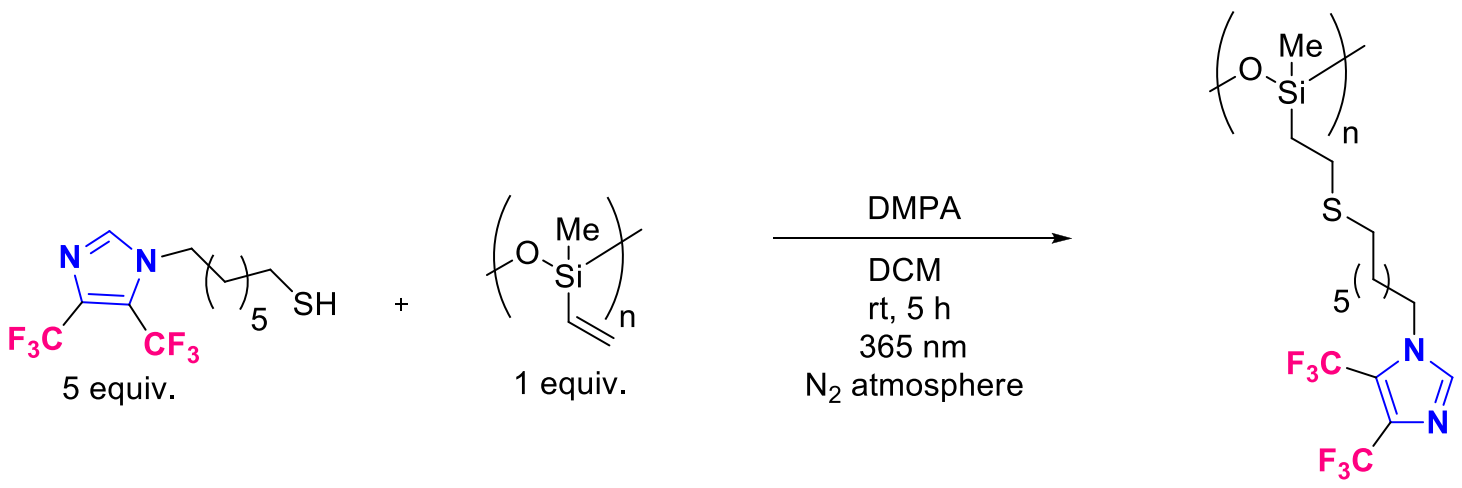

Synthesis of $P M S-10-\operatorname{Im}\left(\mathrm{CF}_{3}\right)_{2}$ : To an oven dried round bottom flask equipped with a magnetic stir bar was added 7-(4,5-bis(trifluoromethyl)-1H-imidazol-1-yl)heptane-1-thiol (5.0 equiv.), PVMS, DMPA (2,2-dimethoxy-2-phenylacetophenone) (10 mol\%) followed by deoxygenated absolute DCM to concertation of 0.1 M in PVMS. This reaction mixture was irradiated with 365 $\mathrm{nm}$ light for 5 hours. Upon completion, the crude mixture was concentrated in vacuo. The polymer was purified by precipitation in diethyl ether, then dried under high vacuum and immediately transferred to a nitrogen filled glove box.

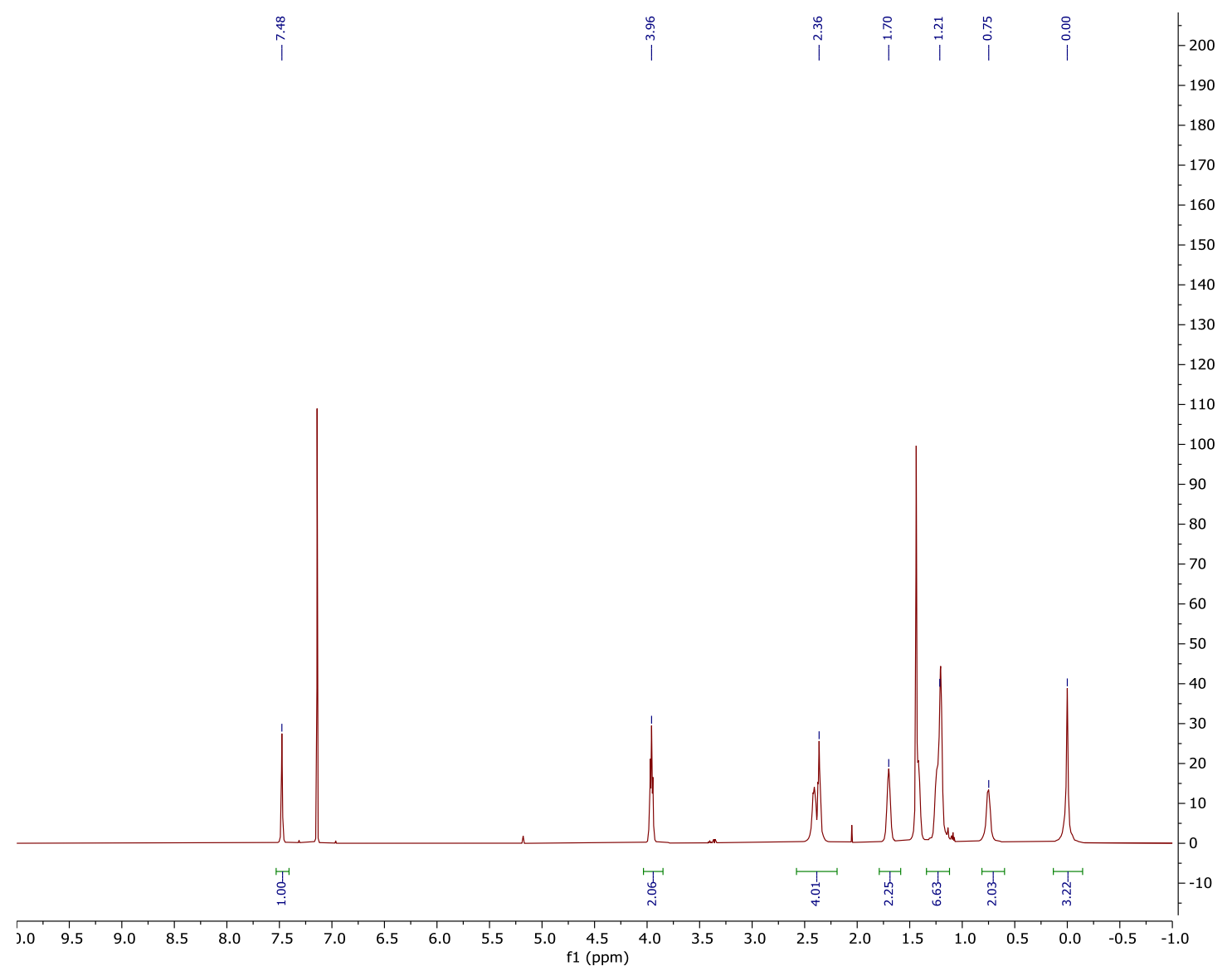

Figure S13. ${ }^{1} \mathrm{H}-\mathrm{NMR}$ of $\mathrm{PMS}-10-\mathrm{Im}\left(\mathrm{CF}_{3}\right)_{2}$ 
<smiles>CC(CS)(CS)Cn1c(Br)nc(Br)c1Br</smiles>

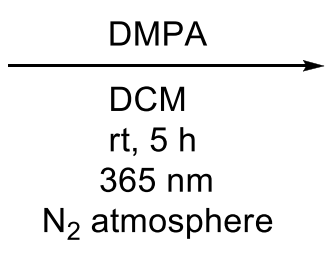

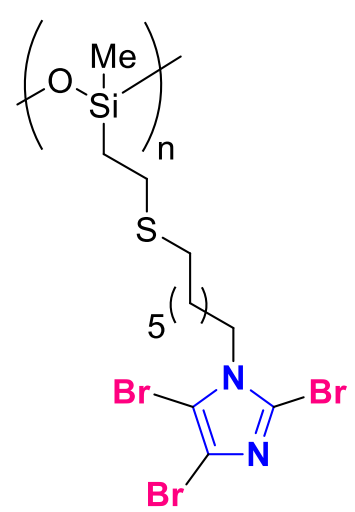

Synthesis of PMS-10-ImBr 3 : To an oven dried round bottom flask equipped with a magnetic stir bar was added 7-(2,4,5-tribromo-1H-imidazol-1-yl)heptane-1-thiol (5.0 equiv.), PVMS, DMPA (2,2-dimethoxy-2-phenylacetophenone) (10 mol\%) followed by deoxygenated absolute DCM to concertation of $0.1 \mathrm{M}$ in PVMS. This reaction mixture was irradiated with $365 \mathrm{~nm}$ light for 5 hours. Upon completion, the crude mixture was concentrated in vacuo. The polymer was purified by precipitation in $\mathrm{MeOH}$, then dried under high vacuum and immediately transferred to a nitrogen filled glove box.

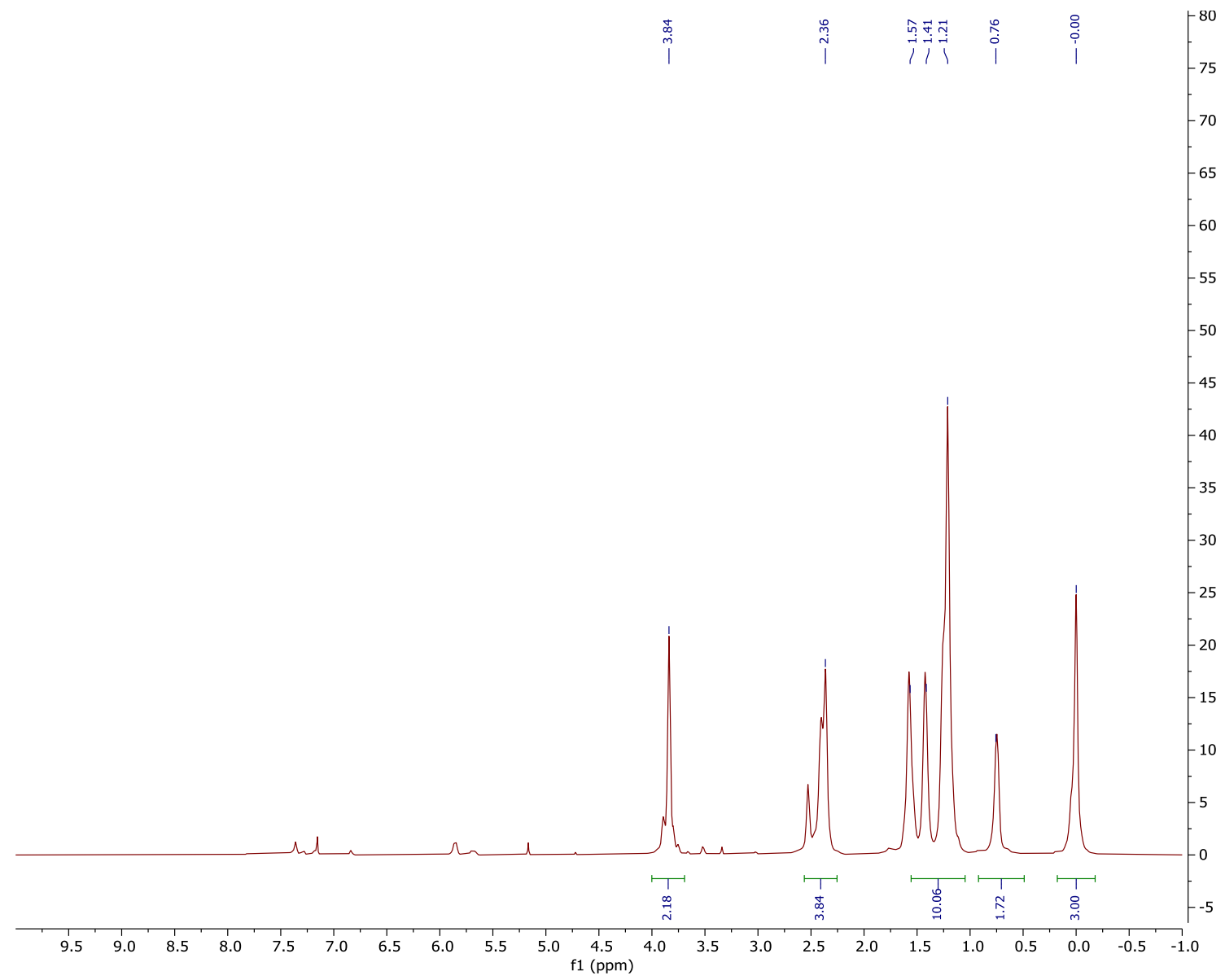

Figure S14. ${ }^{1} \mathrm{H}-\mathrm{NMR}$ of $\mathrm{PMS}-10-\mathrm{ImBr}_{3}$ 
<smiles>CC(C)(CS)Cn1c(Br)nc(Cl)c1Cl</smiles>

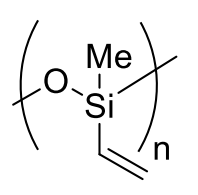

1 equiv.

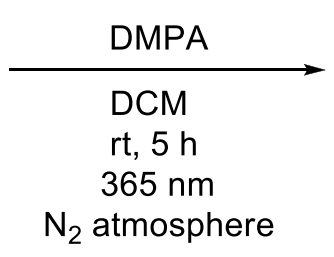

Synthesis of $P M S-10-I m C_{2} B r$ : To an oven dried round bottom flask equipped with a magnetic stir bar was added 7-(2-bromo-4,5-dichloro-1H-imidazol-1-yl)heptane-1-thiol (5.0 equiv.), PVMS, DMPA (2,2-dimethoxy-2-phenylacetophenone) (10 mol\%) followed by deoxygenated absolute DCM to concertation of $0.1 \mathrm{M}$ in PVMS. This reaction mixture was irradiated with $365 \mathrm{~nm}$ light for 5 hours. Upon completion, the crude mixture was concentrated in vacuo. The polymer was purified by precipitation in $\mathrm{MeOH}$, then dried under high vacuum and immediately transferred to a nitrogen filled glove box.

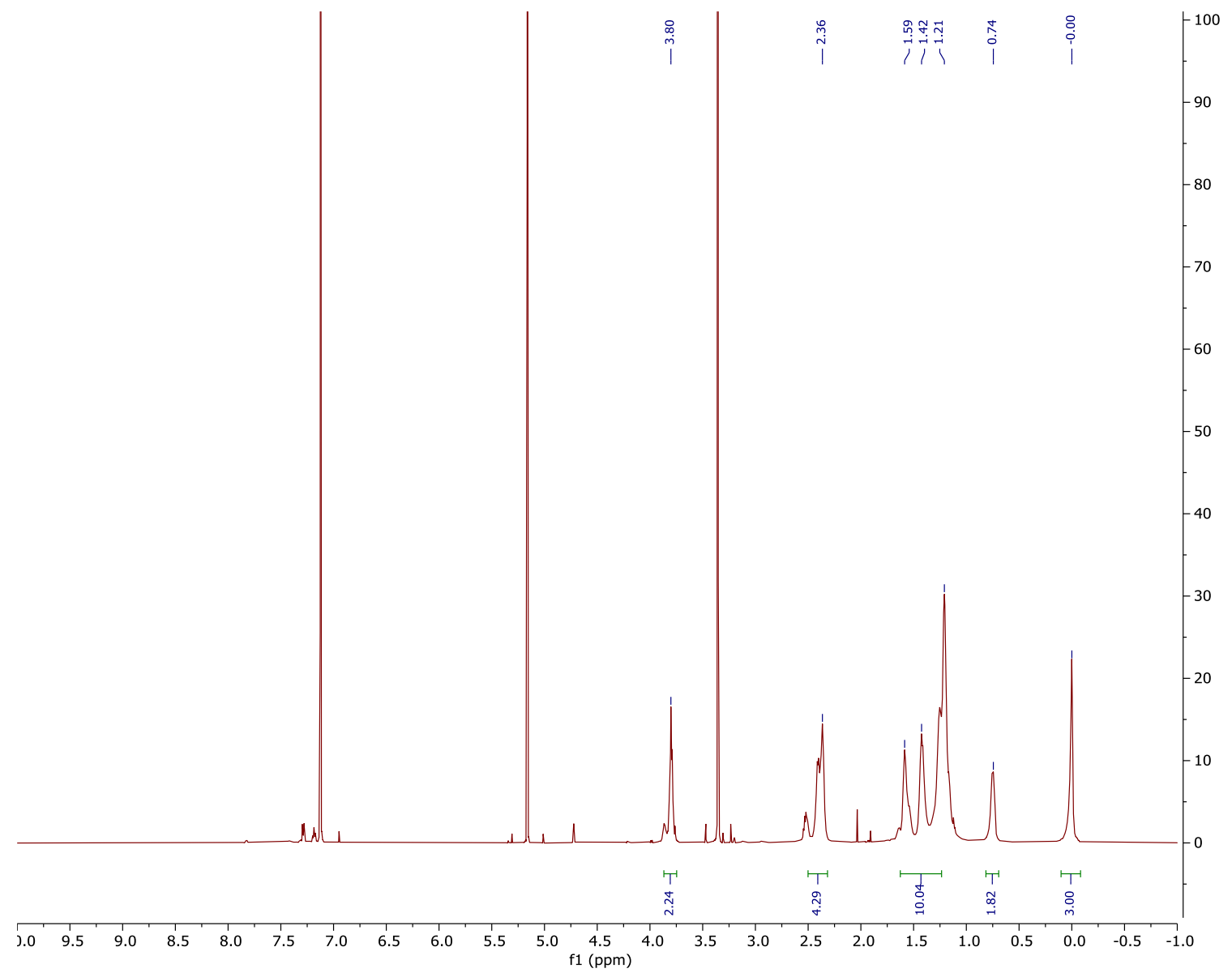

Figure S15. ${ }^{1} \mathrm{H}-\mathrm{NMR}$ of $\mathrm{PMS}-10-\mathrm{ImCl}{ }_{2} \mathrm{Br}$ 


\section{Thermal characterization}

(a)

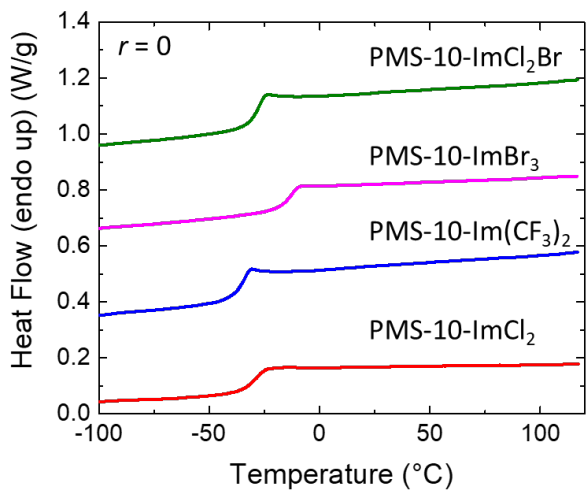

(b)

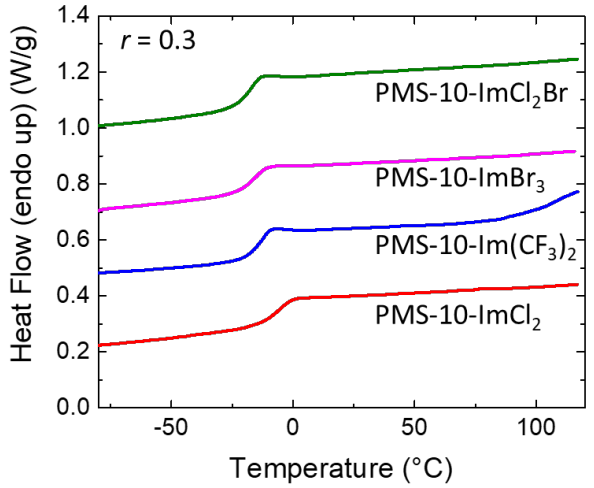

Figure S16. DSC traces for polymers without (a) and with the salt (b).

$\begin{array}{ccccc}\text { Entry } & \text { Substituent } & \boldsymbol{F} & \boldsymbol{R} & \boldsymbol{v} \\ 1 & \mathrm{H} & 0.03 & 0.00 & 0 \\ 2 & \mathrm{Cl} & 0.42 & -0.19 & 0.55 \\ 3 & \mathrm{CF}_{3} & 0.38 & 0.16 & 0.90 \\ 4 & \mathrm{Br} & 0.45 & -0.22 & 0.65\end{array}$

Table S1. Swain-Lupton electronic parameters $(F)$ and $(R)$, and upsilon steric parameter (U), for hydrogen, chlorine, bromine, and trifluoromethyl substituents.

\begin{tabular}{|c|c|c|}
\hline Polymer & Salt concentration $(r)$ & $T_{\mathrm{g}}\left({ }^{\circ} \mathrm{C}\right)$ \\
\hline \multirow{2}{*}{ PMS-10-Im } & 0 & -44.0 \\
\hline & 0.30 & 7.0 \\
\hline \multirow[t]{2}{*}{ PMS-10-ImCl ${ }_{2}$} & 0 & -29.1 \\
\hline & 0.30 & -6.0 \\
\hline \multirow[t]{2}{*}{ PMS-10- $\operatorname{Im}\left(\mathrm{CF}_{3}\right)_{2}$} & 0 & -35.3 \\
\hline & 0.30 & -13.3 \\
\hline \multirow[t]{2}{*}{ PMS-10-ImBr 3} & 0 & -13.6 \\
\hline & 0.30 & -17.0 \\
\hline \multirow[t]{2}{*}{ PMS-10- $\mathrm{ImCl}_{2} \mathrm{Br}$} & 0 & -27.9 \\
\hline & 0.30 & -19.2 \\
\hline
\end{tabular}

Table S2. $T_{\mathrm{g}}$ summary for polymers with and without salt 


\section{A Bode plot of PMS-10-ImCl}

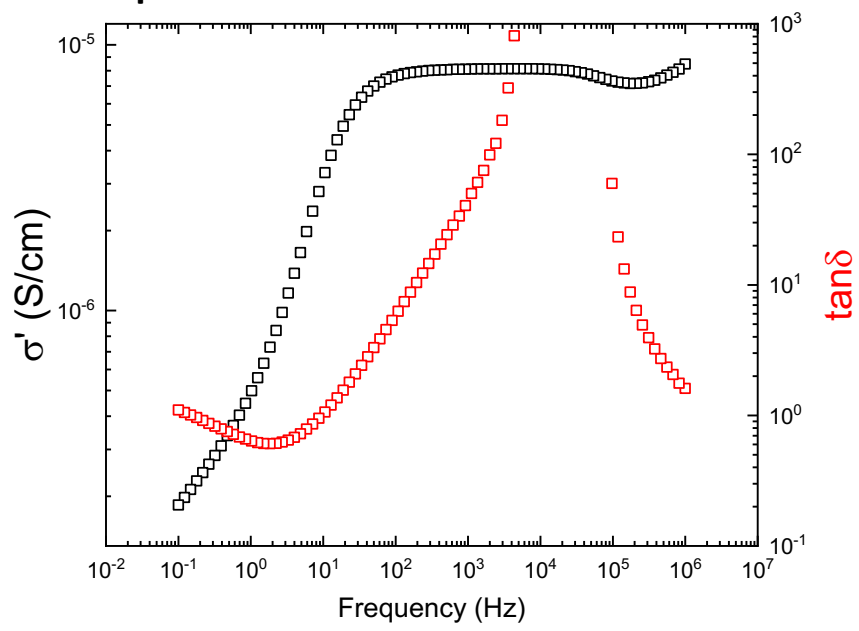

Figure S17. A Bode plot of polymer PMS-10- $\mathrm{ImCl}_{2}(r=0.3)$ recorder at $35^{\circ} \mathrm{C}$

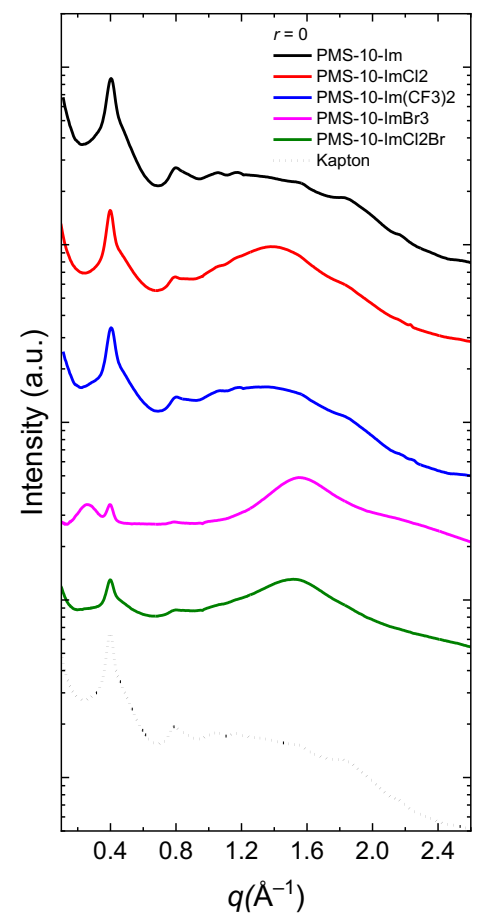

Figure S18. Wide-angle X-ray scattering profiles for polymers at $30^{\circ} \mathrm{C}$ and $r=0.0$

\begin{tabular}{|c|c|c|c|c|c|}
\hline$r$ & PMS-Im & $\mathrm{PMS} \mathrm{ImCl} \mathrm{I}_{2}$ & PMS-Im(CF $)_{2}$ & $\mathrm{PMS} \mathrm{ImBr}_{3}$ & $\mathrm{PMS}-\mathrm{ImCl}_{2} \mathrm{Br}$ \\
\hline 0 & 1.13 & 1.23 & 1.20 & 1.55 & 1.37 \\
\hline 0.3 & 1.26 & 1.33 & 1.29 & 1.60 & 1.45 \\
\hline
\end{tabular}

Table S3. A summary of densities for the five polymers calculated using the Group Contribution Method (GCVOL) 


\section{Dielectric constant measurement for PMS-10-Im( $\left(\mathrm{CF}_{3}\right)_{2}$}

Around 20 mg material was loaded on a 1/4" diameter gold electrode and another gold electrode was placed on top and the the sample was then assembled in a controlled environment sample holder (BioLogic) with a thickness of ca. $0.45 \mathrm{~mm}$. The sample was sealed in the integrated temperature stage (ITS) (BioLogic) and heated to $50{ }^{\circ} \mathrm{C}$ to remove the thermal history. Then the sample was cooled gradually to room temperature, and EIS was performed between $1 \mathrm{MHz}$ to $0.1 \mathrm{~Hz}$ with an amplitude of $100 \mathrm{mV}$. The real part of the dielectric constant $\left(\varepsilon^{\prime}\right)$ was derived from the high-frequency plateau with a phase angle close to $-90^{\circ}$.

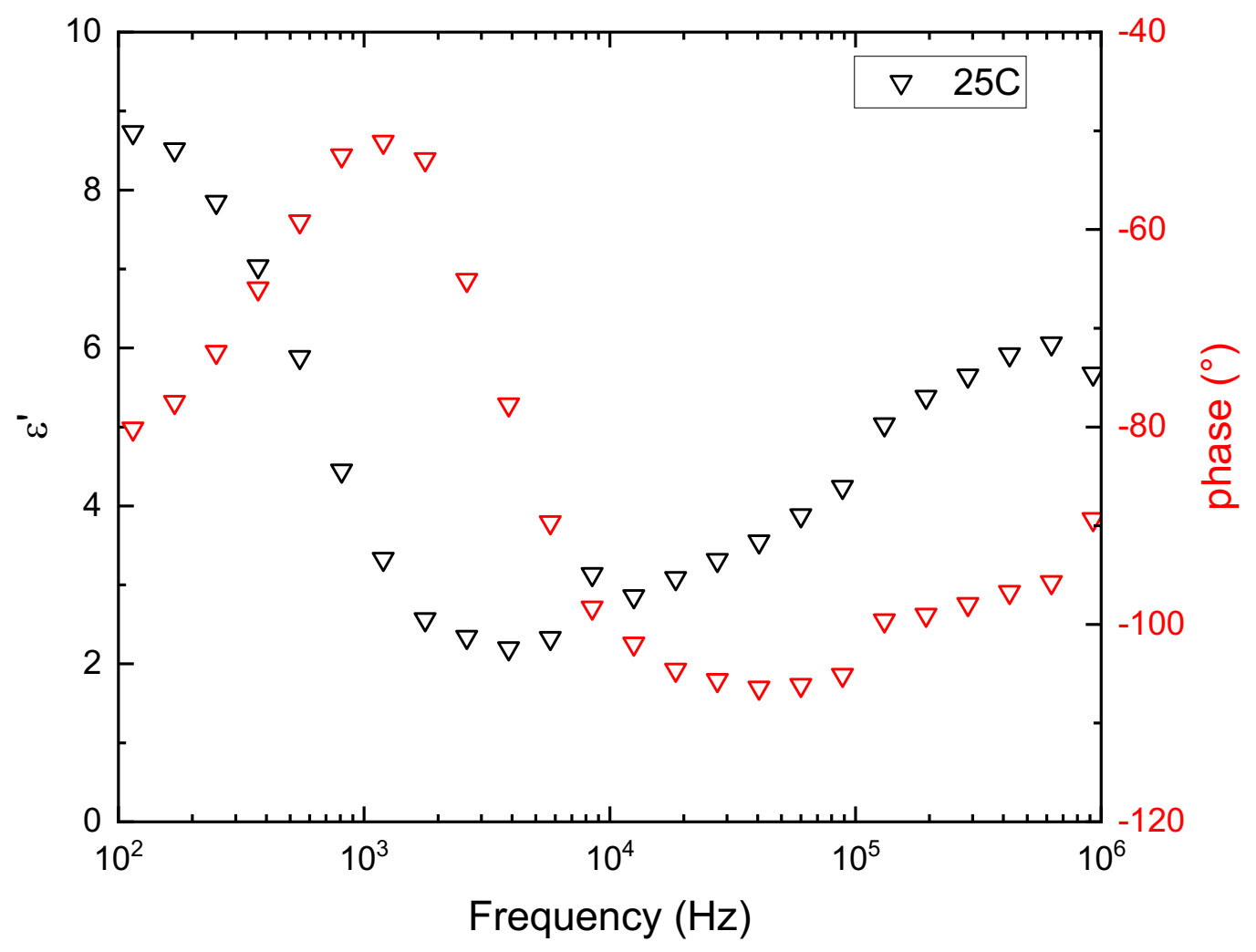

Figure S19. Dielectric constant of PMS-10-Im( $\left(\mathrm{CF}_{3}\right)_{2}$ 


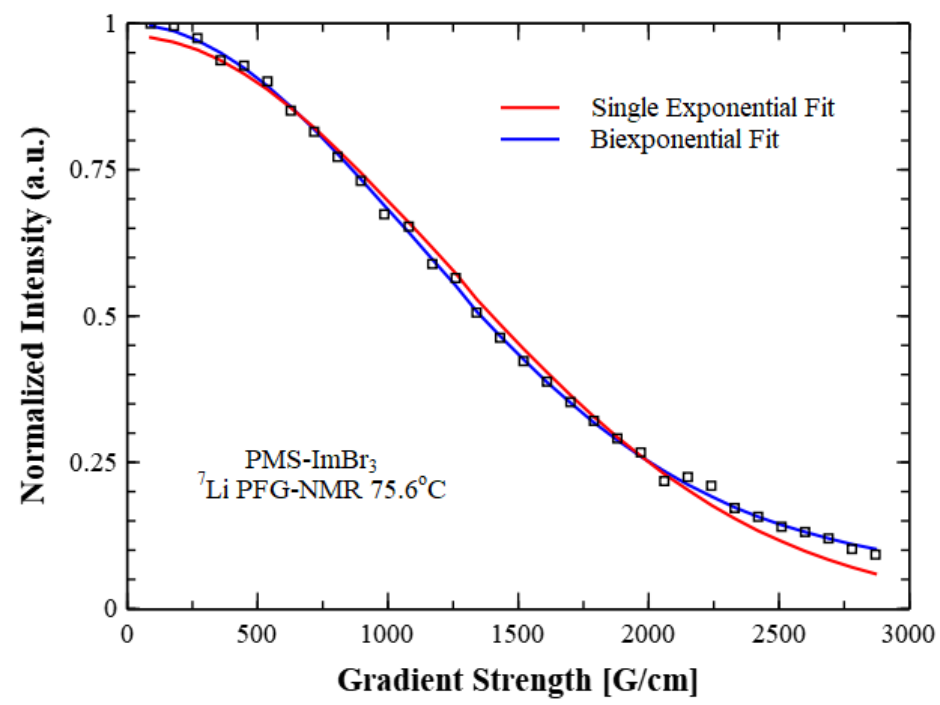

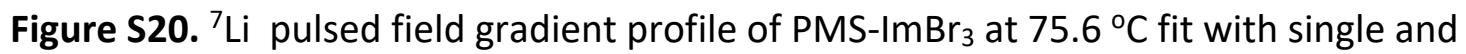
biexpontial decays. The requirement of two signal components suggest the presence of two Liion environments within the polymer electrolyte.

\begin{tabular}{|c|c|c|c|c|c|c|c|}
\hline & \multirow[b]{2}{*}{ Temp. (C) } & \multirow[b]{2}{*}{$\begin{array}{c}\text { 7Li Diffusion } \\
\left(x 10^{-13} \mathrm{~m}^{2} \mathrm{~s}^{-1}\right)\end{array}$} & \multirow[b]{2}{*}{$\begin{array}{c}\text { 19F Diffusion } \\
\left(x 10^{-13} \mathrm{~m}^{2} \mathrm{~s}^{-1}\right)\end{array}$} & \multirow[b]{2}{*}{$t+$} & \multicolumn{2}{|c|}{ Ionic Conductivity (S/cm) } & \multirow[b]{2}{*}{$\begin{array}{c}\text { Haven } \\
\text { Ratio }\left(H_{R}\right) \\
\end{array}$} \\
\hline & & & & & $\begin{array}{c}\text { EIS } \\
\text { Conductivity }\end{array}$ & $\begin{array}{c}\text { NMR } \\
\text { Conductivity }\end{array}$ & \\
\hline \multirow[t]{2}{*}{ PMS-10-Im } & 75.6 & 1.7 & 2 & 0.46 & 7.1E-06 & $1.2 \mathrm{E}-05$ & 0.60 \\
\hline & 84.4 & 3.1 & 4.2 & 0.42 & $1.5 \mathrm{E}-05$ & $2.3 \mathrm{E}-05$ & 0.66 \\
\hline \multirow[t]{3}{*}{ PMS-10-ImCl 2} & 66.7 & 0.48 & 0.87 & 0.36 & $4.2 \mathrm{E}-06$ & 4.1E-06 & 1.0 \\
\hline & 75.6 & 0.94 & 1.4 & 0.40 & 7.7E-06 & $7.0 \mathrm{E}-06$ & 1.1 \\
\hline & 84.4 & 1.7 & 2.5 & 0.40 & $1.4 \mathrm{E}-05$ & $1.2 \mathrm{E}-06$ & 1.1 \\
\hline \multirow[t]{3}{*}{ PMS-10- $\operatorname{Im}\left(\mathrm{CF}_{3}\right)_{2}$} & 66.7 & 0.6 & 0.72 & 0.45 & $3.1 \mathrm{E}-06$ & $3.3 \mathrm{E}-06$ & 0.94 \\
\hline & 75.6 & 1.3 & 1.5 & 0.46 & $5.7 \mathrm{E}-06$ & $6.9 \mathrm{E}-06$ & 0.82 \\
\hline & 84.4 & 2.5 & 2.9 & 0.46 & $1.0 \mathrm{E}-05$ & $1.3 \mathrm{E}-05$ & 0.77 \\
\hline \multirow[t]{3}{*}{ PMS-10-ImBr 3} & 66.7 & 1.1 & 1.1 & 0.5 & $1.8 \mathrm{E}-06$ & $5.70 \mathrm{E}-06$ & 0.31 \\
\hline & 75.6 & 2.1 & 2.3 & 0.48 & $3.1 \mathrm{E}-06$ & $1.0 \mathrm{E}-05$ & 0.28 \\
\hline & 84.4 & 3.7 & 4.3 & 0.46 & $5.2 \mathrm{E}-06$ & $2.0 \mathrm{E}-05$ & 0.26 \\
\hline \multirow[t]{3}{*}{ PMS-10-ImCl $2 \mathrm{Br}$} & 66.7 & 1.1 & 1.2 & 0.48 & $6.3 \mathrm{E}-07$ & $6.3 \mathrm{E}-06$ & 0.1 \\
\hline & 75.6 & 2.2 & 2.4 & 0.48 & $1.3 \mathrm{E}-06$ & $1.2 \mathrm{E}-05$ & 0.11 \\
\hline & 84.4 & 3.9 & 4.3 & 0.48 & $2.4 \mathrm{E}-06$ & $2.2 \mathrm{E}-05$ & 0.11 \\
\hline
\end{tabular}

Relative Uncertainties $\left(u_{r}\right): u_{r}\left(D_{i}\right) \sim 0.05, u_{r}(t+) \sim 0.04, u_{r}(E I S) \sim 0.15, u_{r}(N M R) \sim 0.16, u_{r}\left(H_{R}\right) \sim 0.22$

Table S4. $\mathrm{Li}^{+}$and TFSI ${ }^{-}$self-diffusion coefficients measured with PFG-NMR, $\mathrm{Li}^{+}$transport numbers $\left(t^{+}\right)$, measured and calculated ionic conductivities and Haven ratios for all polymers at various temperatures. 


\section{References}

(1) lizuka, K.; Akahane, K.; Momoee, D. ichi; Nakazawa, M.; Tanouchi, T.; Kawamura, M.; Ohyama, I.; Kajiwara, I.; Iguchi, Y. ichi; Okada, T.; et al. Highly Selective Inhibitors of Thromboxane Synthetase. 1. Imidazole Derivatives. J. Med. Chem. 1981, 24 (10), 11391148.

(2) Schauser, N. S.; Nikolaev, A.; Richardson, P. M.; Xie, S.; Johnson, K.; Susca, E. M.; Wang, H.; Seshadri, R.; Clément, R. J.; Read de Alaniz, J.; Segalman, R. A. Glass Transition Temperature and Ion Binding Determine Conductivity and Lithium-Ion Transport in Polymer Electrolytes. ACS Macro Lett. 2021, 10 (1), 104-109.

(3) Ihmels, E. C.; Gmehling, J. Extension and Revision of the Group Contribution Method GCVOL for the Prediction of Pure Compound Liquid Densities. Ind. Eng. Chem. Res. 2003, 42 (2), 408-412.

(4) Krevelen, D. W. Van; Hoftyzer, P. J. Prediction of Polymer Densities. J. Appl. Polym. Sci. 1969, $13(5), 871-881$. 